Econometrics Working Paper EWP1301

ISSN 1485-6441

University of Victoria

ISSN 1485

Department of Economics

\title{
Modelling Volatility Spillover Effects Between Developed Stock Markets and Asian Emerging Stock Markets
}

\author{
Yanan Li \\ \& \\ David E. Giles \\ Department of Economics, University of Victoria
}

September 2013

\begin{abstract}
This paper examines the linkages of stock markets across the U.S., Japan and six Asian developing countries: China, India, Indonesia, Malaysia, the Philippines and Thailand over the period January 1, 1993 to December 31, 2012. The volatility spillover is modeled through an asymmetric multivariate GARCH model. We find significant unidirectional shock and volatility spillovers from the U.S. market to both the Japanese and the Asian emerging markets. It is also found that the volatility spillovers between the U.S. market and the Asian markets are stronger and bidirectional during the Asian financial crisis. Further, during the last five years, the linkages between the Japanese market and the Asian emerging markets became more apparent. Our paper contributes to the literature by examining both the long run and the short run periods and focusing on shock and volatility spillovers rather than return spillovers, which have been the primary focus of most other studies.
\end{abstract}

Keywords: Volatility, Spillovers, Stock markets, Multivariate GARCH, Asymmetric BEKK model

JEL Classifications: C32, C58, G1

Author Contact: David E. Giles, Dept. of Economics, University of Victoria, P.O. Box 1700, STN CSC, Victoria, B.C., Canada, V8W 2Y2; e-mail: dgiles@uvic.ca; Phone: (250) 721-8540; FAX: 


\section{Introduction}

The increasing economic integration of international stock markets has become especially important over the last two decades. The substantial development of technology and the increased flow of capital between countries are among the main factors contributing to this observed globalization. So, understanding the nature and extent of linkages between different financial markets is important for portfolio managers and financial institutions. The volatility of returns is often used as a crude measure of the risk of holding financial assets (e.g., Brooks, 2002), so, when referring to international equity markets integration, researchers not only investigate returns causality linkages, but they also measure volatility spillover effects. Information about volatility spillover effects is useful for the application of value at risk and hedging strategies.

Recently, with the role of emerging markets becoming more important, economists have focused not only on developed countries (e.g., Theodossiou et al., 1993; Bae et al., 1994; Karolyi 1995), but they have also paid attention to emerging markets (e.g., Worthington et al., 2004; Wang et al., 2004; Goetzmann et al., 2005; Lin et al., 2006; Ng, 2010). For instance, the extent of the linkages between emerging stock markets and developed stock markets has implications for investors in both developing and developed countries. If emerging financial markets are only weakly integrated with their developed counterparts, external shocks may have limited influence on the emerging markets, and then the developed market investors can benefit by including the emerging market stocks in their portfolio, as this diversification should reduce risk. On the contrary, if the emerging stock markets are fully integrated with the developed stock markets, the volatility in the emerging markets may decrease as it will be mainly determined by the developed markets' volatilities, and the domestic emerging investors will benefit from a low cost of capital (Li, 2007).

Thanks to recent developments in econometrics, and the associated software econometrics software ${ }^{1}$, in addition to examining returns spillovers between equity markets, we can now also estimate volatility spillovers between different markets by using multivariate GARCH (MGARCH) models. We take advantage of these developments, by examining linkages between some emerging Asian stock markets and two developed stock markets. The six emerging Asian markets used in this study are China, India, Indonesia, Malaysia, the Philippines and Thailand ${ }^{2}$. We use the U.S. and Japan to represent developed

\footnotetext{
${ }^{1}$ Currently, several packages, such as RATS and SAS, allow us to estimate different types of MGARCH models.

${ }^{2}$ The IMF also includes Pakistan as an emerging market in Asia, but some other major financial institutes do not include Pakistan as an emerging market. Thus, we do not include Pakistan in our sample.
} 
countries in two different geographical regions. We employ an asymmetric BEKK ${ }^{3}$ model proposed by Engle and Kroner (1995), and improved by Kroner and Ng (1998), to examine both shock and volatility spillovers among each emerging market and the two developed markets. Our data sample spans 20 years, and includes both the 1997 Asian financial crisis and the 2007 subprime financial crisis.

Although the empirical finance literature is rich in studies focusing on the transmissions and dynamic linkages between major stock markets, our study distinguishes itself from these in three major respects. First, instead of analyzing transmissions only between developed stock markets, we examine the linkages between the developed markets and Asian emerging markets. Second, we not only examine the long run relationship between different markets, but also compare the results with different sample periods, and the two short-run periods are chosen based on two recent financial crises. Third, and importantly, we consider past shock and volatility spillovers across different markets, whereas the previous literature focuses on returns transmissions.

The remainder of this paper is organized as follows. The next section introduces the background of markets' indices and provides some preliminary statistical analysis of our data. Section 3 outlines the methodology used to analyze the volatility spillover effects, and the empirical results are discussed in section 4. Finally, section 5 summarizes and makes concluding remarks.

\section{Data Analysis}

We used widely accepted benchmark indices for the eight selected countries, with each index describing the overall performance of large-capitalization firms in the respective country, taken to represent the overall equity market in that country. The six Asian emerging stock market indices that we consider are: Shanghai Stock Exchange composite (CHSCOMP) for China; S\&P BSE 30 SENSITIVE (IBOMSEN) for India; IDX composite (JAKCOMP) for Indonesia; FTSE BURSA MALAYSIA KLCI (FBMKLCI) for Malaysia; PSE composite (PSECOMP) for the Philippines; and BANGKOK SET 50 (BNGKS50) for Thailand. The two developed market indices are the S\&P 500 composite (S\&PCOMP) for the U.S.; and TOPIX (TOKYOSE) for Japan. The daily data are obtained from DATASTREAM ${ }^{4}$.

\footnotetext{
${ }^{3}$ The acronym comes from the name of the original collaborators, Baba, Engle, Kraft and Kroner. This is explained by Engle and Kroner (1995, footnote 1$)$.

${ }^{4}$ The DATASTREAM code for each index is given in parentheses.
} 
The full sample period under study is from January 1, 1993, to December 31, 2012, except for Thailand ${ }^{5}$ due to data limitations. The reason for selecting this period is that both the Asian financial crisis and the subprime financial crisis are covered, so in addition to investigating the volatility performance over the long run, we can also explore dynamic linkages across markets over the short run, or over an economic recovery period.

Figure 1: Trading Hours for the U.S. and Asian Stock

\section{Markets}

\begin{tabular}{|l|c|l|c|}
\hline Country & Local trading hours & Country & Local trading hours \\
\hline U.S. & $9: 30-16: 00$ & India & $9: 00-15: 00$ \\
\hline Japan & $9: 00-15: 00$ & Malaysia & $9: 00-17: 00$ \\
\hline China & $9: 30-15: 00$ & The Philippines & $9: 30-15: 30$ \\
\hline Indonesia & $9: 30-16: 00$ & Thailand & $9: 30-16: 30$ \\
\hline
\end{tabular}

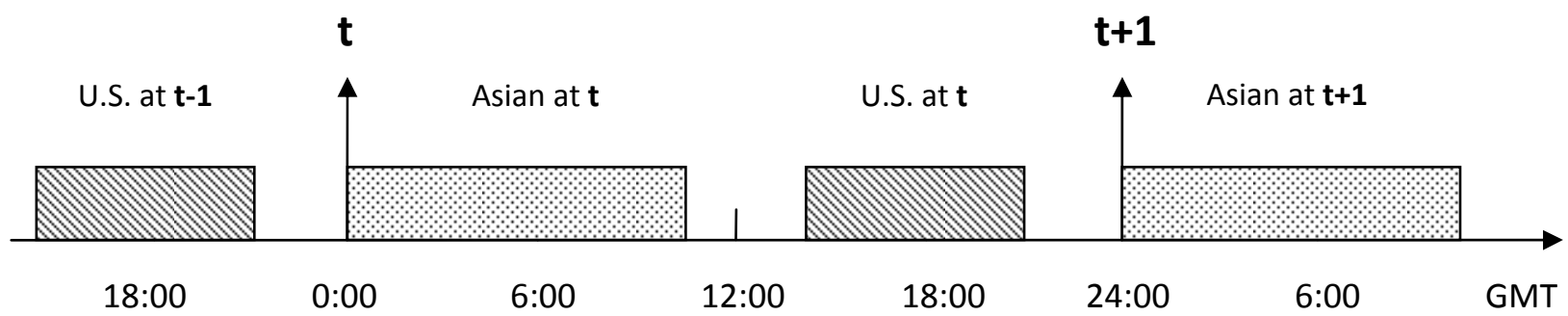

There are 5217 observations in our sample. By using daily data, we can capture more information than with weekly or monthly data. In this study, we set prices on non-trading days to be the same as on the previous trading day. ${ }^{6}$ Also, our markets are located in different time zones, resulting in different opening and closing times, as is shown in Figure 1 for two consecutive days.

Figure A-1 in the Appendix shows the adjusted closing prices of our eight indices. Each index has a trough during 1998 when the Asian financial crisis happened. The troughs in Japan, Indonesia, Malaysia, the Philippines and Thailand are more obvious than those in the U.S., China, and India. However, when the U.S. subprime financial crisis occurred in 2007, each index has a clear trough. Visually, the markets' integrations are more apparent over the last decade, than during the 1990's.

\footnotetext{
${ }^{5}$ Thailand's index is from January 1, 1996, to December 31, 2012.

${ }^{6}$ We found that excluding the implied zero returns for certain days did not yield significantly different results.
} 
The continuously compounding daily returns for each stock market are expressed in percentages, computed by multiplying the first difference of the logarithm of the market closing value of the index by 100. Figure A-2 in the Appendix shows the returns series for each index. These series exhibit the typical 'volatility clustering' of high frequency financial data. Table 1 presents the descriptive statistics of the stock price returns for the eight indices over the full sample period.

Table 1: Summary statistics for returns series - Full sample

\begin{tabular}{lllllllll}
\hline \hline Country & \multicolumn{1}{c}{ USA } & \multicolumn{1}{c}{ JPN } & CHN & \multicolumn{1}{c}{ IDN } & \multicolumn{1}{c}{ IND } & \multicolumn{1}{c}{ MYS } & \multicolumn{1}{c}{ PHL } & \multicolumn{1}{c}{ THA } \\
\hline Mean & 0.0227 & -0.0080 & 0.0205 & 0.0528 & 0.0384 & 0.0185 & 0.0294 & -0.0012 \\
Median & 0.0256 & 0 & 0 & 0.0122 & 0 & 0 & 0 & 0 \\
Maximum & 10.957 & 12.865 & 28.860 & 13.128 & 15.990 & 20.817 & 16.178 & 12.589 \\
Minimum & -9.470 & -10.007 & -17.905 & -12.732 & -11.809 & -24.153 & -13.089 & -17.231 \\
Std.Dev & 1.192 & 1.298 & 2.120 & 1.544 & 1.603 & 1.374 & 1.429 & 1.899 \\
Skewness & -0.2366 & -0.2346 & 1.0817 & -0.1934 & -0.0721 & 0.4427 & 0.2547 & 0.2241 \\
Kurtosis & 11.730 & 9.611 & 23.687 & 11.858 & 8.513 & 53.111 & 13.858 & 10.056 \\
Jarque-Bera & 16611 & 9545 & 94028 & 17086 & 6610 & 545918 & 25681 & 9238 \\
(p-value) & $(0.00)$ & $(0.00)$ & $(0.00)$ & $(0.00)$ & $(0.00)$ & $(0.00)$ & $(0.00)$ & $(0.00)$ \\
\# of days & 5216 & 5216 & 5216 & 5216 & 5216 & 5216 & 5216 & 4435 \\
\hline \multirow{2}{*}{ LB-Q(12) } & 55.90 & 37.20 & 87.47 & 159.21 & 83.00 & 97.08 & 156.3 & 71.28 \\
& $(0.00)$ & $(0.00)$ & $(0.00)$ & $(0.00)$ & $(0.00)$ & $(0.00)$ & $(0.00)$ & $(0.00)$ \\
LB-Q(24) & 89.77 & 45.27 & 100.29 & 208.88 & 100.05 & 140.76 & 171.81 & 110.40 \\
& $(0.00)$ & $(0.005)$ & $(0.00)$ & $(0.00)$ & $(0.00)$ & $(0.00)$ & $(0.00)$ & $(0.00)$ \\
LB-Qs(12) & 4751.8 & 3682.6 & 1622.8 & 1103.0 & 949.05 & 2509.4 & 359.84 & 1219.6 \\
& $(0.00)$ & $(0.00)$ & $(0.00)$ & $(0.00)$ & $(0.00)$ & $(0.00)$ & $(0.00)$ & $(0.00)$ \\
LB-Qs(24) & 7396.8 & 4565.8 & 1831.5 & 1911.0 & 1319.9 & 2681.0 & 514.44 & 1562.0 \\
& $(0.00)$ & $(0.00)$ & $(0.00)$ & $(0.00)$ & $(0.00)$ & $(0.00)$ & $(0.00)$ & $(0.00)$ \\
\hline \hline
\end{tabular}

Note: LB-Q(12) and (24) are the Ljung-Box Q-statistics for the returns series up to 12 and 24 lags. LB-Qs(12) and (24) are the Ljung-Box Q-statistics for the squared returns series.

Except for Japan and Thailand, the mean returns of the other six indices are all slightly positive. Moreover, the U.S. stock index is the least volatile, having the smallest standard deviation (1.192) among all eight countries; and the other developed stock market - Japan - has the second smallest standard deviation (1.298). Thus, the developed stock markets are more stable than the emerging stock markets during the sample period. Compared to the other emerging markets, China's stock return can be considered as the most volatile series with a standard deviation of 2.120. Based on the sample skewness statistics, large negative returns are more common than large positive returns in the U.S., Japanese, Indonesian and Indian markets. In contrast, the returns for Malaysia, the Philippines, Thailand and especially China have a positive skewness. All of the returns series are leptokurtic, a characteristic 
expected with high frequency financial return series. Table 1 also gives Q-statistics and their p-values for the Ljung and Box (1979) tests. Based on the Q-statistics reported, we can strongly reject the null hypothesis of zero correlation, meaning that all of the returns series and their squared values ${ }^{7}$ are autocorrelated. We also tested the stationarity of the returns series for each market using both the Augmented Dickey-Fuller (ADF) test of Said and Dickey (1984), and the KPSS test (Kwiatkowski et al., 1992). As expected, the tests' results indicated that all of the returns series are stationary.

In addition to using the full sample period, we also use two sub-sample periods. The first of these is from 1997-2001, which includes the Asian financial crisis, and the second period is from 2008 to 2012, which includes the U.S. subprime financial crisis ${ }^{8}$. These two periods are considered because changes in market correlations take place on a continuous basis and arise not only as a result of market crashes but also as a consequence of many major economic, financial, and political events (e.g., He, 2001).

\section{Methodology}

In standard VAR modelling, the disturbance vector is assumed to be an unobservable zero mean white noise vector process, with a time invariant covariance matrix. However, financial analysts noticed that the data for returns on financial assets typically exhibits so-called "volatility clustering”, (Fama, 1965 and Mandelbrot, 1963), leading to the consideration of modeling time-varying second-order moments. Autogressive Conditional Heteroskedasticity (ARCH) models (Engle, 1982) and Generalized ARCH (GARCH) models (Bollerlev, 1986), are designed to model such features. Multivariate GARCH models and their extensions are widely used by the applied financial researchers. For example, Bollerslev et al. (1988) use a multivariate GARCH $(1,1)-\mathrm{M}$ formulation in the implementation of a CAPM model for a market portfolio. Bauwens et al. (2006) distinguish three non-mutually exclusive approaches for constructing multivariate GARCH models based on different specification of the conditional variancecovariance matrix $\mathrm{H}_{\mathrm{t}}$ : (1) direct generalizations of the univariate GARCH model of Bollerslev (1986), such as VEC, BEKK and factor models; (2) linear combinations of univariate GARCH models, such as (generalized) orthogonal models and latent factor models; (3) nonlinear combinations of univariate GARCH models, such as constant and dynamic conditional models.

Bollerslev et al. (1988) first proposed a general VEC model in which each element of $H_{t}$ is a linear function of the lagged squared errors and cross-products of errors and lagged values of the elements of $\mathrm{H}_{\mathrm{t}}$.

\footnotetext{
${ }^{7}$ The squared returns can be used as a proxy for volatility, so this suggests that there are correlations in the variances, which can be modeled as conditional heteroskedasticity

${ }^{8}$ The summary statistics for the two sub-samples are available on request.
} 
For example, in the n-equation $\operatorname{VEC}(1,1)^{9}$ model the conditional covariance matrix is defined as:

$\operatorname{vech}\left(H_{t}\right)=c+\operatorname{Avech}\left(\varepsilon_{t-1} \varepsilon_{t-1}^{\prime}\right)+\operatorname{Gvech}\left(H_{t-1}\right)$

Where the vech(.) operator stacks the lower triangular portion of a symmetric matrix into a vector. However, the limitation of this model is the large number of parameters that need to be estimated. The number of parameters is $n(n+1)(n(n+1)+1) / 2$, so even in a simple case with $n=2(p=1, q=1)$, there are still 21 parameters to be estimated. If $n=3,78$ parameters have to be estimated. Additionally, it is difficult to guarantee the positivity of $\mathbf{H}_{\mathbf{t}}$ without imposing strong restrictions on the parameters (Gourieroux, 1997). To overcome this problem, Bollerslev et al. (1988) suggest the diagonal VEC (DVEC) model in which the $\mathbf{A}$ and $\mathbf{G}$ matrices are assumed to be diagonal, and this restriction reduces the number of parameters to $n(n+5) / 2$, which means that even if $n=3$, there are only 12 parameters (Bauwens et al., 2006). Nevertheless, as the $\mathbf{A}$ and $\mathbf{G}$ matrices are diagonal, each element of $\mathbf{H}_{\mathbf{t}}$ depends only on its own lag and on the previous value of the shocks. Thus, the DVEC model cannot capture volatility spillover effects between different markets, and also the diagonal VECH model still cannot guarantee that $\mathbf{H}_{\mathbf{t}}$ is positive definite.

In order to overcome these two problems, Engle and Kroner (1995) propose the BEKK model, which generates a new parameterization of $\mathbf{H}_{\mathbf{t}}$. In the $\operatorname{BEKK}(1,1)$ model the conditional covariance matrix is defined as:

$H_{t}=C^{\prime} C+A^{\prime} \varepsilon_{t-1} \varepsilon_{t-1}^{\prime} A+G^{\prime} H_{t-1} G$

where $\mathbf{C}$ is an $(n \times n)$ lower triangular matrix of parameters, and $\mathbf{A}$ and $\mathbf{G}$ are $(n \times n)$ parameter matrices. The BEKK model guarantees positive semi-definiteness by working with quadratic forms. In addition, as with the GJR-model in the univariate case, there is interest in extending the multivariate GARCH model to allow for the asymmetric responses of volatility. In particular, stock price volatility tends to be greater in response to negative shocks than to positive shocks. Kroner and $\mathrm{Ng}$ (1998) extend the BEKK model to capture this asymmetric property of the time-varying variance-covariance:

$H_{t}=C^{\prime} C+A^{\prime} \varepsilon_{t-1} \varepsilon_{t-1}^{\prime} A+G^{\prime} H_{t-1} G+D^{\prime} \epsilon_{t-1} \epsilon_{t-1}^{\prime} D$

where $\epsilon_{t}$ is defined as $\varepsilon_{t}$ if $\varepsilon_{t}$ is negative, and zero otherwise. The diagonal elements of the matrix $\mathbf{A}\left(\mathbf{a}_{\mathrm{ii}}\right)$ measure the effect of shocks on its own country's volatility, and the off-diagonal elements of the matrix A $\left(\mathbf{a}_{\mathbf{i j}}\right)$ capture the effect of country $i$ 's shock on country j's volatility, in order to measure the linkages or

\footnotetext{
${ }^{9}$ In order to simplify the equation, we show only the first lagged order for the following models, but these models can be extended to higher orders.
} 
transmissions between country $i$ and country $j$. In the above equation, to save space, we omit the asymmetric terms, as the parameter matrix $\mathbf{D}$ has a similar expression to the matrix A. However, the parameters in the matrix D measure the asymmetric response to the negative shocks or 'bad news'. The past volatility effects are measured by the matrix $\mathbf{G}$. The diagonal elements of matrix $\mathbf{G}$ ( $\mathbf{g}_{\mathbf{i i}}$ ) capture the own past volatility effect on its conditional variance, and the off-diagonal parameters in the matrix $\mathbf{G}$ ( $\mathbf{g}_{\mathrm{ij}}$ ) measure the effects of past volatility of market $i$ on market $j$ 's conditional variance, also known as “volatility spillover”.

In addition, just as we confirm the lag order for the VAR model, in order to model the variancecovariance equation, we should also confirm the lag order for the BEKK model. In most cases, the GARCH (1,1) specification is adequate (e.g., Engle, 1995; Bollerslev et al., 1992). However, Bodurtha and Mark (1991) and Attanasio (1991) find that a high order of the ARCH term is needed to remove the ARCH effect in the residuals. French and Roll (1986) also find the well-known weekend effect where the variance of returns tends to be higher on days following closures of the market, and this can lead to highorder ARCH models. In this study, we choose the BEKK $(1,1)$ to model the variance-covariance equation, for two reasons. First, this is found to be adequate in terms of the usual diagnostic tests. Second, both the BEKK model and the VAR model include a large numbers of parameters, and if we increase the lag order for the BEKK model, this poses practical computational issues.

Engle and Kroner (1995) and Kroner and Ng (1998) note that the above system can be estimated efficiently and consistently using full information maximum-likelihood method. Let $L_{t}$ be the $\log$ likelihood function of observation $t$, and let $n$ be the number of stock indices. $L$ is the joint $\log$ likelihood function assuming normally distributed errors ${ }^{10}$, given by:

$L=\sum_{t=1}^{T} L_{t}$

$L_{t}=-\frac{n}{2} \ln (2 \pi)-\frac{1}{2} \ln \left|H_{t}\right|-\frac{1}{2} \varepsilon_{t}^{\prime} H_{t}^{-1} \varepsilon_{t}$

where $T$ is the number of sample observations. Computation has been implemented in RATS 8.2. As recommended by Engle and Kroner (1995), several iterations were performed with the simplex algorithm, which is a derivative-free method, to obtain the initial values for the parameters. The BFGS (Broyden,

\footnotetext{
${ }^{10}$ We also considered models with Student t-distributed errors, but the results were less satisfactory than those based on normally distributed errors.
} 
1970; Fletcher, 1970; Goldfarb, 1970; and Shanno, 1970) algorithm is then employed to obtain the final estimates and their asymptotic standard errors.

\section{Empirical Results}

Given the number of countries under study, we have divided them into six groups, with each group including the U.S., Japan and one of the emerging markets. We use the numbers 1, 2 and 3 to denote the U.S. market, the Japanese market and the investigated emerging market, respectively. In each case, as the series are stationary, we adopted a VAR (4) specification for the mean equation for the full sample estimation, and a VAR (2) model ${ }^{11}$ for the sub-sample analysis. An asymmetric GARCH-BEKK $(1,1)$ model was used for the variance-covariance equation in each case.

As a diagnostic check we have used the Ljung-Box test to the residuals of our multivariate model. If the mean equation is correctly specified, all Q-statistics for the residuals themselves should be insignificant; and if the variance equation is correctly specified, all Q-statistics for the squared residuals should be insignificant. The test statistics and their p-values are reported in the Appendix tables. We choose to report the $24^{\text {th }}$ and $36^{\text {th }}$ the lag order statistics. However, choosing the order of the lag to use for the test is an open problem. Harvey (1981) notes that if we choose a lag that is too small, the test may not detect serial correlation at high-order lags. However, if we choose a lag that is too large, the test may have low power. Additionally, “As a rule of thumb, a given autocorrelation coefficient is classed as significant if it is outside a $\left[ \pm 1.96 * 1 /(T)^{1 / 2}\right]$ band, where $T$ is the number of observations.” (Brooks, 2002, p.264) Since our dataset is of a daily frequency and spans a long period, $T$ is relatively larger in this study than in the literature which uses weekly data. These statistics suggest that we cannot reject the null hypotheses for both tests, leading us to believe that our specifications are reasonable. Although the statistics for the $24^{\text {th }}$ lag order for Indonesia suggests that we should reject no serial correlation at the $1 \%$ significant level for the squared residuals, the Q statistics indicate that the $\operatorname{BEKK}(1,1)$ is reasonable for Indonesia.

It must be kept in mind that the BEKK model is different from the linear regression model, with the parameters estimated by the BEKK model being hard to interpret. Additionally, in order to indicate the overall impacts, we calculated the average estimated value for each parameter across the six groups from Table $1^{12}$, and the complete estimation results are reported in Table A-1 of the Appendix.

\footnotetext{
${ }^{11}$ Based on the usual lag selection criteria, a VAR (2) model is adequate for the mean equation for the sub-sample periods.

${ }^{12}$ We give each parameter an equal weight, as we consider each emerging market we examined to be equally important. We also calculate a standard error for each average number by giving equal weights. Moreover, as the
} 


\subsection{Evidence of stock market linkages from the full sample period}

The full sample, which covers 20 years, can be used to analyze the long run transmissions between the developed equity markets and the emerging markets that we are studying. The estimation results are presented in Table 2, Panel A. The diagonal elements of the matrix A measure the effect of own past shocks on that series' own conditional variance. As shown in Table 2, the average values of the estimated diagonal elements of $\mathbf{A}$ are all significantly different from zero. If we compare the magnitude of the average values for these three parameters, then the shock of an emerging market has the largest effect (0.2361) on its own conditional variance, and the U.S. stock market has the smallest own shock effect (0.0488). This result indicates that past shocks play a greater role in the volatility of the emerging markets than those in the volatility of the developed markets, and this can be explained by the fact that the more mature a market is, the less affected by it is by its own past shocks.

We also consider the asymmetric response of volatility, and the diagonal elements of the matrix $\mathbf{D}$ capture the asymmetric response of a market to its own past negative shocks or "bad news". The asymmetric responses are highly significant, but the average values of $d_{11}, d_{22}$ and $d_{33}$ indicate that developed countries have a more evident response to negative shocks than do emerging markets. The magnitude of the U.S. stock market's reaction to its own negative shocks is 0.3391 , and that for the emerging market is only 0.2363 . Moreover, for both the U.S. and Japan, the negative shocks have a greater effect $(0.3391$, $0.2886)$ than the effects from the overall shocks $(0.0488,0.1592)$ on its own conditional variance; but for the emerging markets, the magnitudes of the overall shock effect $(0.2361)$ and the negative shock effect (0.2363) are almost the same.

The diagonal parameters in the matrix $\mathbf{G}$ measure the effect of past volatility of a market on its conditional variance. All of the estimated parameters on the diagonal of $\mathbf{G}$ are significantly different from zero at the $1 \%$ level. Also, the magnitudes of these estimates are close to one, which indicates a typical characteristic of financial data - a high degree of volatility persistence. The volatility persistence is lower for the emerging stock markets than for the U.S. stock market, indicating that the emerging markets derive relatively less of their volatility persistence from own past volatility than do the developed markets.

An important aspect of our work is to analyze transmissions across markets, such as shock and volatility spillovers, which can be captured by the off-diagonal parameters of the matrices $\mathbf{A}, \mathbf{G}$ and $\mathbf{D}$. First, we focus on the off-diagonal elements of the matrix $\mathbf{A}$, which indicate the overall shock spillovers among the

parameters in the BEKK model are shown in quadratic form, we use the absolute value of each coefficient to calculate the mean. 
U.S., Japan and the six Asian developing countries. From Table 2, there are significant shock spillovers from the U.S. stock market to the Asian stock markets, as both $a_{12}$ and $a_{13}$ are significantly different from zero. The average values of the estimates of $a_{12}$ and $a_{13}$ are, respectively, 0.1335 and 0.0829 , which means the transmissions are stronger between developed markets than between a developed market and the emerging markets, in the long run. However, there is not enough evidence to show that the shocks of the Japanese market also affect the volatility of the U.S. stock market. Thus, there is only a weak unidirectional past shock spillover between the U.S. stock market and the Japanese stock market. Also, there is only a weak past shock spillover from some emerging markets to the U.S. market. It seems that our results support the conventional expectation that the spillover is usually from a developed market to a less developed or emerging market.

However, there is one thing that requires attention, and that is the issue of different time zones. We cannot exclude the possibility that these highly significant shock spillovers from the U.S. market to the Asian markets are partly due to the quick spread of information. Moreover, no evidence indicates there are past shock spillovers from the Japanese stock market to the emerging markets. Overall, we indeed have evidence showing that there are past shock spillovers among the U.S., Japan and the Asian developing countries, and these transmissions are consistent with the "global center' hypothesis, that a global center, such as the U.S., plays a major role in the transmission of news that is macroeconomic in nature (Li, 2007, 2012).

If we consider only negative shocks, the previous existing transmissions are no longer significant. From Table 2, there is no significant "bad news" spillover from the U.S. market to the Japanese market. In addition, if we do not distinguish between positive and negative shocks, the past innovation effect from the U.S. market on emerging markets (0.0829) is smaller than that on the Japanese market (0.1335). However, if we focus only on negative shocks, the emerging stock markets have a slightly greater reaction (0.0344) to past negative shocks from the U.S. than from the Japanese stock market (0.0310). Moreover, the average values of $d_{12}$ and $d_{13}(0.0310$ and 0.0344$)$ are far less than those of $a_{12}$ and $a_{13}$ (0.1335 and 0.0829). These results suggest that the overall shock spillovers are much stronger than "bad news” spillovers from the U.S. market to Asian markets. Summarizing the two different shock spillovers, the overall shock spillovers across markets are more likely to happen, and have greater impacts, than the negative shock spillovers in the long run.

In the case of volatility spillovers, the only highly significant one is that from the Japanese stock market to the Asian emerging stock markets, where the average value is 0.0195 . However, this spillover is only unidirectional, since the estimates of $g_{32}$ are not significantly different from zero. Unlike the overall past 
shock spillovers, we find no evidence to show there are significant volatility spillovers from the U.S. stock market to Asian stock markets during the full sample period. However, there is evidence indicating a very weak volatility spillover from the Asian markets to the U.S. market, which is suggested by the average values of $g_{21}$ and $g_{31}$. In general, the volatility spillovers are not as obvious as the shock spillovers when estimated using our full sample period.

\subsection{Evidence of stock market linkages from the two sub-samples}

The previous results are based on the full sample, spanning from 1993 to 2012. We find some evidence of linkages across different markets in the long run. In this subsection, we examine whether these transmissions still exist in the short run, and we compare the short run and the long run results. The two sub-samples we choose are based on the occurrence of two major financial crises, and each sub-sample spans five years. We include five years of data in each case because, as pointed out by He (2001), changes in market correlations take place on a continuous basis and arise not only as the result of a market crash, but also as a consequence of many major economic, financial, and political events.

\subsubsection{Asian financial crisis period (January 1997 to December 2001)}

Our first sub-sample straddles the period associated with the Asian financial crisis. This crisis started in July 1997 with the devaluation of Thai baht, and then rapidly spread to other economies in Southeast Asia through trade channels. Table 2, Panel B shows our estimation results for this period ${ }^{13}$. Most diagonal parameters from the matrices $\mathrm{A}$ and $\mathrm{D}$ are still significantly different from zero except for the average value of $a_{11}$, which is not significant in the sub-sample estimation. It seems that in the short run, the volatility of the U.S. stock market is not influenced by its own past shocks. Compared with the full sample estimation, the average estimated value of $a_{22}$ is smaller (0.0765), but the average value of $\mathrm{a}_{33}$ is larger (0.2833), than that in the full sample estimation. The reason may be that the Asian emerging markets were not stable during this period and were much more easily influenced by the previous shocks. Although there are no significant own shock effects for the U.S. market during this time, the value of $d_{11}$ shows that the U.S. market is still influenced by its past "bad news", and also the average value of $d_{11}$ is almost unchanged compared with the average value in the full sample. As with the overall shock effects, the negative shock effects on the volatility during this time are smaller for the Japanese stock market (0.2198) and larger for the emerging markets (0.2930), compared with these average values in the long run. The diagonal parameters of the matrix $G$ are still highly significantly different from zero, but the magnitudes for these parameters are smaller than those in the full sample period. The result suggests that own-volatility effects had less influence during the Asian financial crisis than over the full period.

\footnotetext{
${ }^{13}$ The complete estimation results based on this sub-sample are reported in Tables A-2 and A-3 of the Appendix.
} 
However, the spillovers across the markets in the short run seem to be more apparent than those in the long run period. During this period, we find a significant bidirectional shock spillover between the U.S. market and the Japanese market, through the estimates of $\mathrm{a}_{12}$ and $\mathrm{a}_{21}$. However, in the sub-sample estimation, there is no evidence to show that there are any significant linkages between developed markets and the emerging markets. The negative shock spillovers have similar effects. There is still a bidirectional linkage between the U.S. and Japan, but in this case the average effect of the negative shock spillover from Japan to the U.S. is not strongly significant. Apart from this linkage, the other average values of the parameters are not significantly different from zero. Table 2, Panel B, also presents the volatility spillovers. In contrast to the full sample estimation results, we find a strong bidirectional volatility spillover between the U.S. stock market and the Japanese stock market. The average values of $\mathrm{g}_{13}$ and $\mathrm{g}_{31}$ imply that we also find strong bidirectional volatility spillovers between the U.S. market and the emerging markets. During the Asian financial crisis period, the volatility spillovers across different markets were more active than those in the full sample, but there is no evidence indicating that the past volatility of the emerging markets was transmitted to the Japanese market.

\subsubsection{The U.S. Subprime financial crisis period (January 2008-1-1 to December 2012)}

The Asian financial crisis happened in the 1990's, and with the development of technology and global interactions, the short run linkages between the developed markets and the emerging markets may have changed since then. So, we also consider a more recent period - the last five years in the dataset, which covers the subprime financial crisis of the U.S.. The estimation results for this case are shown in Table 2, Panel C.

The diagonal elements of the matrices $\mathbf{A}$ and $\mathbf{D}$ are still highly significantly different from zero, except $a_{11}$. This means that, except for the U.S. stock market, both the Japanese and the emerging markets are influenced by their own past shocks in both the short run and the long run, suggesting that the more mature the market, the less reactions there are to the past innovations. However, the mature market will have a greater reaction than the emerging markets to negative shocks. In addition, the estimated values of the diagonal elements of $\mathbf{G}$ indicate a high degree of persistence, but the magnitudes for Japan and the developing countries are smaller here than those estimated using in the full sample. 
Table 2: Estimation results

\begin{tabular}{|c|c|c|c|c|c|c|}
\hline \multicolumn{3}{|c|}{ A } & \multirow[t]{2}{*}{ G } & \multicolumn{3}{|c|}{ D } \\
\hline \multicolumn{6}{|c|}{ Panel A: Full sample period } & \\
\hline$(1,1)$ & $0.0488 * * *$ & $(0.0185)$ & $0.9635^{* * *}$ & $(0.0028)$ & $0.3391 * * *$ & $(0.0149)$ \\
\hline$(1,2)$ & $0.1335^{* * *}$ & $(0.0137)$ & 0.0016 & $(0.0042)$ & 0.0310 & $(0.0209)$ \\
\hline$(1,3)$ & $0.0829 * * *$ & $(0.0137)$ & 0.0043 & $(0.0039)$ & $0.0344^{*}$ & $(0.0208)$ \\
\hline$(2,1)$ & 0.0132 & $(0.0093)$ & $0.0067 *$ & $(0.0037)$ & $0.0235^{*}$ & $(0.0123)$ \\
\hline$(2,2)$ & $0.1592 * * *$ & $(0.0158)$ & $0.9345^{* * *}$ & $(0.0060)$ & $0.2886^{* * *}$ & $(0.0206)$ \\
\hline$(2,3)$ & 0.0185 & $(0.0150)$ & $0.0195^{* * *}$ & $(0.0060)$ & $0.0432 * *$ & $(0.0204)$ \\
\hline$(3,1)$ & $0.0143^{* *}$ & $(0.0067)$ & $0.0051^{* *}$ & $(0.0023)$ & 0.0135 & $(0.0100)$ \\
\hline$(3,2)$ & $0.0167 *$ & $(0.0093)$ & 0.0021 & $(0.0039)$ & $0.0311^{*}$ & $(0.0179)$ \\
\hline$(3,3)$ & $0.2361^{* * *}$ & $(0.0139)$ & $0.9507^{* * *}$ & $(0.0042)$ & $0.2363^{* * *}$ & $(0.0239)$ \\
\hline \multicolumn{7}{|c|}{ Panel B: Asian financial crisis period } \\
\hline$(1,1)$ & 0.0398 & $(0.0390)$ & $0.8141^{* * *}$ & $(0.0244)$ & $0.3355^{* * *}$ & $(0.0444)$ \\
\hline$(1,2)$ & $0.1829 * * *$ & $(0.0331)$ & $0.2700^{* * *}$ & $(0.0309)$ & $0.1519 * * *$ & $(0.0498)$ \\
\hline$(1,3)$ & 0.0640 & $(0.0463)$ & $0.1220^{* * *}$ & $(0.0343)$ & $0.1338 * *$ & $(0.0603)$ \\
\hline$(2,1)$ & $0.1087 * * *$ & $(0.0365)$ & $0.2400^{* * *}$ & $(0.0257)$ & $0.0804 *$ & $(0.0463)$ \\
\hline$(2,2)$ & $0.0765^{*}$ & $(0.0399)$ & $0.8674^{* * *}$ & $(0.0204)$ & $0.2198 * * *$ & $(0.0450)$ \\
\hline$(2,3)$ & 0.0629 & $(0.0444)$ & $0.0495^{*}$ & $(0.0277)$ & 0.1004 & $(0.0625)$ \\
\hline$(3,1)$ & 0.0199 & $(0.0193)$ & $0.0371^{* * *}$ & $(0.0104)$ & 0.0331 & $(0.0270)$ \\
\hline$(3,2)$ & 0.0074 & $(0.0194)$ & 0.0213 & $(0.0150)$ & 0.0230 & $(0.0273)$ \\
\hline$(3,3)$ & $0.2833^{* * *}$ & $(0.0363)$ & $0.9017^{* * *}$ & $(0.0187)$ & $0.2930^{* * *}$ & $(0.0579)$ \\
\hline \multicolumn{7}{|c|}{ Panel C: Subprime financial crisis period } \\
\hline$(1,1)$ & 0.0367 & $(0.0348)$ & $0.9518^{* * *}$ & $(0.0059)$ & $0.3848 * * *$ & $(0.0252)$ \\
\hline$(1,2)$ & $0.1258 * * *$ & $(0.0351)$ & $0.0234^{* *}$ & $(0.0109)$ & $0.1485^{* * *}$ & $(0.0390)$ \\
\hline$(1,3)$ & $0.1305^{* * *}$ & $(0.0302)$ & 0.0137 & $(0.0104)$ & $0.0838 * *$ & $(0.0372)$ \\
\hline$(2,1)$ & 0.0258 & $(0.0237)$ & 0.0169 & $(0.0171)$ & $0.0550 *$ & $(0.0302)$ \\
\hline$(2,2)$ & $0.1629 * * *$ & $(0.0461)$ & $0.8442^{* * *}$ & $(0.0221)$ & $0.3312^{* * *}$ & $(0.0495)$ \\
\hline$(2,3)$ & $0.0670^{* *}$ & $(0.0286)$ & $0.0884^{* * *}$ & $(0.0261)$ & $0.0950^{* *}$ & (0.0391) \\
\hline$(3,1)$ & $0.0470 *$ & $(0.0274)$ & 0.0121 & $(0.0144)$ & 0.0496 & $(0.0410)$ \\
\hline$(3,2)$ & $0.0926^{* * *}$ & $(0.0314)$ & $0.0677^{* * *}$ & $(0.0232)$ & 0.0577 & $(0.0462)$ \\
\hline$(3,3)$ & $0.1924 * * *$ & $(0.0336)$ & $0.9100^{* * *}$ & (0.0193) & $0.2825^{* * *}$ & $(0.0464)$ \\
\hline
\end{tabular}

Note: $* * *, * *$ and $*$ denote significance at the $1 \%, 5 \%$, and $10 \%$ levels respectively. Values in parentheses are asymptotic standard errors. 
Consistent with the long run results, the U.S. stock market plays an important role as its past shocks highly affect both the Japanese market and the emerging markets' current volatility, and this applies not only for the overall shocks but also for negative shocks. We also find a significant bidirectional shock spillover between the Japanese market and the emerging markets during this time. However, if we consider the negative shocks separately, the negative shock spillovers from the emerging markets do not affect the Japanese market's volatility, since the average value of $d_{32}$ is close to zero. In contrast to the volatility spillovers occurring in the first sub-sample period, in the more recent years, only $g_{23}$ and $g_{32}$ are highly significantly different from zero. Recalling that the value of $a_{23}$ and $a_{32}$ are also significantly different from zero during this period, we can say that there are not only shock spillovers but also volatility spillovers between the Japanese stock market and the emerging stock markets. Nevertheless, we find no evidence showing that there is a connection between the U.S. market and the Asian emerging markets. If we compare the average value of $g_{23}$ in the long-run (0.0195) and in the short-run (0.0844), we can conclude that the linkage between these two markets became stronger recently.

\section{Conclusions}

For both the long run and the short run, the emerging markets are more affected by their own past shocks, as compared to the developed markets. The extent of the own shock effect is almost the same for the U.S. market, but the gap of the own shock effects between the Japanese market and the emerging markets became smaller from the late 1990's to the most recent five years. However, these findings change if we consider just "bad news”. The U.S. stock market has the greatest own negative shock effect among all the markets we analyzed, and this is robust across both the short run and the long run periods. The results indicate that the emerging markets seem to be more affected by "good news". Nevertheless, no matter which market is examined, the negative effects are stronger than the overall effects. The own past volatility effects are highly significant for all cases, and the U.S. market has the highest degree of persistence when we consider the full sample period. However, during the Asian financial crisis subsample period, the own past volatility effect for the U.S. market became the smallest one, and the Asian emerging markets had the highest average value of this effect. The results suggest that the U.S. market derives relatively more of its volatility persistence outside the domestic market, probably coming from Asian markets since the financial crisis.

In addition to analyzing the own shock and volatility influences, we also focus on the shock and volatility spillovers across different markets. The U.S. stock market, as the central one in the world, has unidirectional shock spillovers to both the Japanese and the emerging stock markets, and these transmissions are robust across both the long run and the short run. Especially for the emerging markets, 
the extent of these spillovers from the U.S. market not only became more apparent, but also became higher than those for the Japanese market over the recent five years. When we consider the negative shocks separately, these unidirectional spillovers still exist significantly in the short run, but not in the long run. Moreover, during the recent five years, there are significant bidirectional shock spillovers between the Japanese market and the emerging markets, which are not found by the previous literature. In contrast to the shock spillovers, the volatility spillovers from the U.S. to other countries are strongly significant only for the Asian financial crisis period, and at the same time, the past volatility of the emerging markets also are transmitted to the U.S. market. Although we do not find shock spillovers from Japan to the Asian developing countries in the long run, the volatility spillovers between them are significant in both the long run and the short run. Particularly, during the recent five years, the linkages between the Japanese market and the Asian emerging markets have become stronger.

\section{Acknowledgements}

We are grateful to Judith Clarke and to participants at the Society for Computational Economics (CEF 2013) conference in Vancouver, B.C., 2013, for their helpful comments. 


\section{References}

Attanasio, O. P. (1991). Risk, time-varying second moments and market efficiency. Review of Economic Studies, 58, 479-494.

Bae, K., and Karolyi, G.A. (1994). Good news, bad news and international spillovers of stock return volatility between Japan and the U.S.. Pacific-Basin Finance Journal, 2, 405-438.

Bauwens, L., Laurent, S., and Rombouts, J. V. K. (2006). Multivariate GARCH models: A survey. Journal of Applied Econometrics, 21, 79-109.

Bodurtha, J. N., and Mark, N. C. (1991). Testing the CAPM with Time-Varying risks and returns. Journal of Finance, 46, 1485-1505.

Bollerslev, T. (1986). Generalized autoregressive conditional heteroskedasticity. Journal of Econometrics, 31, 307-327.

Bollerslev, T., Chou, R. Y., and Kroner, K. F. (1992). ARCH modeling in finance. Journal of Econometrics, 52, 5-59.

Bollerslev, T., Engle, R. F., and Wooldridge, J. M. (1988). A capital asset pricing model with timevarying covariances. Journal of Political Economy, 96, 116-131.

Brooks, C. (2002). Introductory Econometrics for Finance. Cambridge University Press: New York.

Broyden, C. G. (1970). The convergence of a class of double-rank minimization algorithms. Journal of the Institute of Mathematics and Its Applications, 6, 76-90.

Engle, R. F. (1982). Autoregressive conditional heteroscedasticity with estimates of the variance of United Kingdom inflation. Econometrica, 50, 987-1007.

Engle, R. F., ed. (1995). ARCH: Selected Readings. Oxford University Press: New York.

Engle, R. F., and Kroner, K. F. (1995). Multivariate simultaneous generalized ARCH. Econometric Theory, 11, 122-150.

Fama, E. F. (1965). The behavior of stock-market prices. Journal of Business, 38, 34-105.

Fletcher, R. (1970). A new approach to variable metric algorithms. Computer Journal, 13, 317-322.

Goetzmann, W. N., Li, L., and Rouwenhorst, K. G. (2005). Long-term global market correlations. Journal of Business, 78, 1-38.

Goldfarb, D. (1970). A family of variable metric updates derived by variational means. Mathematics of Computation, 24, 23-26.

Gourieroux, C. (1997). ARCH Models and Financial Applications. Springer: New York.

He, L. T. (2001). Time variation paths of international transmission of stock volatility - the U.S. vs. Hong Kong and South Korea. Global Finance Journal, 12, 79-93. 
Karolyi, G. A. (1995). A multivariate GARCH model of international transmissions of stock returns and volatility: The case of the United States and Canada. Journal of Business and Economic Statistics, 13, 11-25.

Kroner, K. F., and Ng, V. K. (1998). Modeling asymmetric comovements of asset returns. Review of Financial Studies, 11, 817-844.

Kwiatkowski, D., Phillips, P. C. B., Schmidt, P., and Shin, Y. (1992). Testing the null hypothesis of stationarity against the alternative of a unit root. Journal of Econometrics, 54, 159-178.

Li, H. (2007). International linkages of the Chinese stock exchanges: A multivariate GARCH analysis. Applied Financial Economics, 17, 285-297.

Li, H. (2012). The impact of China's stock market reforms on its international stock market linkages. Quarterly Review of Economics and Finance, 52, 358-368.

Lin, J., and Wu, C. (2006). Modeling China's stock markets and international linkages. Journal of the Chinese Statistical Association, 44, 1-31.

Ljung, G. M., and Box, G. E. P. (1978). On a measure of lack of fit in time series models. Biometrika, 65, 297-303.

Mandelbrot, B. (1963). The variation of certain speculative prices. Journal of Business, 36, 394-419.

Ng, A. (2000). Volatility spillover effects from Japan and the U.S. to the Pacific-Basin. Journal of International Money and Finance, 19, 207-233.

Said, S. E., and Dickey, D. A. (1984). Testing for unit roots in autoregressive-moving average models of unknown order. Biometrika, 71, 599-607.

Shanno, D. F. (1970). Conditioning of quasi-Newton methods for function minimization. Mathematics of Computation, 24, 647-656.

Theodossiou, P., and Lee, U. (1993). Mean and volatility spillovers across major national stock markets: Further empirical evidence. Journal of Financial Research, 16, 337-350.

Wang, P., Wang, P., and Liu, A. (2004). Return and risk interactions in Chinese stock markets. Journal of International Financial Markets, Institutions \& Money, 14, 367-383.

Worthington, A., and Higgs, H. (2004). Transmission of equity returns and volatility in Asian developed and emerging markets: A multivariate GARCH analysis. International Journal of Finance \& Economics, 9, 71-80. 
Table A1-1: Full sample estimation results - China

\begin{tabular}{|c|c|c|c|c|c|c|}
\hline \multirow[b]{2}{*}{$R_{\mathrm{i} 1}(\mathbf{1})$} & \multicolumn{2}{|c|}{ USA(i = 1) } & \multicolumn{2}{|c|}{$\operatorname{JPN}(\mathrm{i}=2)$} & \multicolumn{2}{|c|}{$\operatorname{CHN}(\mathbf{i}=3)$} \\
\hline & -0.0141 & $(0.0163)$ & $0.4432 * * *$ & $(0.0122)$ & $0.1149 * * *$ & $(0.0176)$ \\
\hline $\mathbf{R}_{\mathrm{i1}}(2)$ & -0.0093 & $(0.0144)$ & $0.0652 * * *$ & $(0.0116)$ & $0.0320 * *$ & $(0.0140)$ \\
\hline $\mathbf{R}_{\mathrm{i} 1}(\mathbf{3})$ & $-0.0371^{* * *}$ & (0.0128) & 0.0074 & $(0.0092)$ & $-0.0214^{*}$ & $(0.0127)$ \\
\hline $\mathbf{R}_{\mathrm{i} 1}(\mathbf{4})$ & -0.0161 & $(0.0136)$ & $0.0296 * * *$ & $(0.0113)$ & 0.0107 & $(0.0147)$ \\
\hline$R_{\mathrm{i} 2}(1)$ & -0.0037 & (0.0105) & -0.0057 & $(0.0113)$ & -0.0046 & (0.0098) \\
\hline $\mathbf{R}_{\mathrm{i} 2}(2)$ & $0.0213^{*}$ & $(0.0111)$ & 0.0059 & $(0.0081)$ & -0.0016 & $(0.0120)$ \\
\hline $\mathbf{R}_{\mathrm{i} 2}(\mathbf{3})$ & 0.0112 & (0.0103) & $-0.0176^{*}$ & $(0.0105)$ & 0.0113 & $(0.0140)$ \\
\hline $\mathbf{R}_{\mathrm{i} 2}(4)$ & $-0.0260 * *$ & $(0.0102)$ & -0.0010 & $(0.0075)$ & 0.0203* & (0.0109) \\
\hline $\mathbf{R}_{\mathrm{i} 3}(\mathbf{1})$ & -0.0080 & $(0.0054)$ & -0.0069 & $(0.0067)$ & -0.0088 & $(0.0113)$ \\
\hline $\mathbf{R}_{\mathrm{i} 3}(2)$ & -0.0003 & $(0.0052)$ & 0.0007 & $(0.0066)$ & -0.0066 & $(0.0092)$ \\
\hline $\mathbf{R}_{\mathrm{i3}}(\mathbf{3})$ & 0.0025 & $(0.0052)$ & 0.0005 & $(0.0066)$ & $0.0316^{* * *}$ & $(0.0079)$ \\
\hline $\mathbf{R}_{\mathrm{i} 3}(4)$ & -0.0031 & $(0.0054)$ & 0.0057 & $(0.0068)$ & 0.0189* & $(0.0114)$ \\
\hline Constant & $0.0340 * * *$ & $(0.0125)$ & -0.0055 & $(0.0140)$ & 0.0036 & $(0.0154)$ \\
\hline$C(\mathbf{i}, \mathbf{1})$ & $0.1119 * * *$ & (0.0079) & $-0.0387 * *$ & $(0.0151)$ & $0.0367 * *$ & $(0.0166)$ \\
\hline$C(\mathbf{i}, 2)$ & & & $0.1936^{* * *}$ & $(0.0145)$ & $0.0784^{* * *}$ & $(0.0170)$ \\
\hline$C(\mathbf{i}, 3)$ & & & & & $0.1296^{* * *}$ & $(0.0165)$ \\
\hline$A(\mathbf{i}, \mathbf{1})$ & -0.0004 & $(0.0154)$ & $-0.0199 * *$ & $(0.0094)$ & 0.0011 & $(0.0028)$ \\
\hline$A(i, 2)$ & $0.1271^{* * *}$ & $(0.0126)$ & $0.1988^{* * *}$ & $(0.0125)$ & $0.0061^{*}$ & $(0.0037)$ \\
\hline A $(\mathbf{i}, 3)$ & $0.0334^{* * *}$ & $(0.0128)$ & 0.0128 & $(0.0126)$ & $0.2195^{* * *}$ & $(0.0107)$ \\
\hline G (i,1) & $0.9609 * * *$ & (0.0028) & $0.0111^{* * *}$ & $(0.0031)$ & -0.0011 & $(0.0008)$ \\
\hline$G(\mathbf{i}, 2)$ & 0.0034 & (0.0035) & $0.9377 * * *$ & $(0.0050)$ & -0.0004 & $(0.0013)$ \\
\hline G (i,3) & -0.0011 & (0.0036) & $-0.0154 * * *$ & $(0.0051)$ & $0.9676^{* * *}$ & $(0.0024)$ \\
\hline$D(\mathbf{i}, \mathbf{1})$ & $-0.3598 * * *$ & $(0.0152)$ & $0.0229 *$ & $(0.0121)$ & $0.0137 * *$ & $(0.0066)$ \\
\hline$D(\mathbf{i}, 2)$ & $0.0278^{*}$ & $(0.0163)$ & $-0.2505 * * *$ & $(0.0201)$ & 0.0072 & $(0.0091)$ \\
\hline D (i,3) & $-0.0398 * *$ & (0.0199) & $-0.0537 * *$ & $(0.0210)$ & $0.1782^{* * *}$ & $(0.0221)$ \\
\hline MVLB-Q(24) & & $218.86(0.4$ & & & & \\
\hline MVLB-Q(36) & & $336.61(0.3$ & & & & \\
\hline MVLB-Qs(24) & & $165.24(0.9$ & & & & \\
\hline MVLB-Qs(36) & & $329.94(0.3$ & & & & \\
\hline
\end{tabular}

Note: ${ }^{* * *},{ }^{* *}$ and $*$ denote significance at the $1 \%, 5 \%$, and $10 \%$ levels respectively; Values in parentheses are asymptotic standard errors; MVLB-Q(24) and (36) stand for the Ljung-Box Q-statistic for the standardized residuals up to 24 and 36 lags while MVLB-Qs(24) and (36) stand for the Ljung-Box Q statistic for the squared standardized residuals. 
Table A1-2: Full sample estimation results - Indonesia

\begin{tabular}{|c|c|c|c|c|c|c|}
\hline \multirow[b]{2}{*}{$R_{\mathrm{i} 1}(\mathbf{1})$} & \multicolumn{2}{|c|}{$\operatorname{USA}(i=1)$} & \multicolumn{2}{|c|}{$\operatorname{JPN}(i=2)$} & \multicolumn{2}{|c|}{$\operatorname{IDN}(i=3)$} \\
\hline & $-0.0217 *$ & $(0.0125)$ & $0.4376^{* * *}$ & $(0.0106)$ & $0.3158^{* * *}$ & $(0.0121)$ \\
\hline $\mathbf{R}_{\mathrm{i} 1}(\mathbf{2})$ & -0.0075 & $(0.0120)$ & $0.0581^{* * *}$ & $(0.0105)$ & 0.0022 & $(0.0121)$ \\
\hline $\mathbf{R}_{\mathrm{i} 1}$ (3) & $-0.0395 * * *$ & $(0.0127)$ & 0.0116 & $(0.0096)$ & $0.0518^{* * *}$ & $(0.0102)$ \\
\hline $\mathbf{R}_{\mathrm{i1}}(\mathbf{4})$ & -0.0131 & $(0.0127)$ & $0.0322^{* * *}$ & $(0.0111)$ & $0.0337 * * *$ & $(0.0110)$ \\
\hline $\mathbf{R}_{\mathrm{i} 2}(\mathbf{1})$ & -0.0048 & $(0.0095)$ & -0.0047 & $(0.0113)$ & $-0.0633^{* * *}$ & $(0.0107)$ \\
\hline $\mathbf{R}_{\mathrm{i} 2}(2)$ & $0.0232 * *$ & $(0.0099)$ & 0.0044 & $(0.0081)$ & 0.0044 & $(0.0089)$ \\
\hline $\mathbf{R}_{\mathrm{i} 2}(\mathbf{3})$ & 0.0110 & $(0.0094)$ & -0.0135 & $(0.0102)$ & 0.0146 & $(0.0100)$ \\
\hline $\mathbf{R}_{\mathrm{i} 2}(\mathbf{4})$ & $-0.0261^{* * *}$ & $(0.0094)$ & 0.0031 & $(0.0101)$ & $0.0258^{* *}$ & $(0.0107)$ \\
\hline $\mathbf{R}_{\mathrm{i} 3}(\mathbf{1})$ & 0.0054 & $(0.0078)$ & 0.0083 & $(0.0084)$ & $0.1590^{* * *}$ & $(0.0128)$ \\
\hline $\mathbf{R}_{\mathrm{i} 3}(2)$ & -0.0015 & $(0.0081)$ & -0.0001 & $(0.0078)$ & 0.0034 & $(0.0108)$ \\
\hline $\mathbf{R}_{\mathrm{i} 3}(\mathbf{3})$ & 0.0047 & $(0.0079)$ & -0.0038 & $(0.0087)$ & -0.0101 & $(0.0105)$ \\
\hline $\mathbf{R}_{\mathrm{i3}}(\mathbf{4})$ & -0.0039 & $(0.0087)$ & -0.0044 & $(0.0085)$ & 0.0106 & $(0.0127)$ \\
\hline Constant & $0.0361^{* * *}$ & $(0.0105)$ & -0.0096 & $(0.0142)$ & $0.0390 * * *$ & $(0.0129)$ \\
\hline$C(\mathbf{i}, \mathbf{1})$ & $0.1040^{* * *}$ & $(0.0069)$ & 0.0086 & $(0.0216)$ & $0.0455^{* *}$ & $(0.0208)$ \\
\hline$C(\mathbf{i}, 2)$ & & & $0.2107 * * *$ & $(0.0143)$ & $0.0407^{* *}$ & $(0.0200)$ \\
\hline$C(\mathbf{i}, 3)$ & & & & & $0.1736^{* * *}$ & $(0.0155)$ \\
\hline$A(\mathbf{i}, 1)$ & $0.0793^{* * *}$ & $(0.0226)$ & 0.0094 & $(0.0088)$ & -0.0053 & $(0.0127)$ \\
\hline$A(i, 2)$ & $-0.0957 * * *$ & $(0.0147)$ & $-0.1635^{* * *}$ & $(0.0141)$ & -0.0015 & $(0.0112)$ \\
\hline$A(i, 3)$ & $-0.1321^{* * *}$ & $(0.0141)$ & $-0.0509 * * *$ & (0.0139) & $0.2085^{* * *}$ & $(0.0147)$ \\
\hline G (i,1) & $0.9653^{* * *}$ & $(0.0027)$ & 0.0032 & $(0.0030)$ & -0.0027 & $(0.0029)$ \\
\hline G $(\mathbf{i}, 2)$ & 0.00005 & $(0.0040)$ & $0.9356^{* * *}$ & $(0.0053)$ & -0.0007 & $(0.0072)$ \\
\hline G $(\mathbf{i}, 3)$ & 0.0019 & $(0.0045)$ & $-0.0237 * * *$ & $(0.0066)$ & $0.9463 * * *$ & (0.0049) \\
\hline$D(\mathbf{i}, \mathbf{1})$ & $0.3244^{* * *}$ & $(0.0163)$ & $-0.0272 * * *$ & $(0.0097)$ & 0.0061 & $(0.0115)$ \\
\hline$D(\mathbf{i}, 2)$ & 0.0282 & $(0.0206)$ & $0.2954 * * *$ & $(0.0175)$ & $0.0255^{*}$ & $(0.0147)$ \\
\hline$D(\mathbf{i}, 3)$ & 0.0034 & $(0.0237)$ & 0.0287 & $(0.0191)$ & 0.2991 & $(0.0205)$ \\
\hline MVLB-Q(24) & & 210.54 & & & & \\
\hline MVLB-Q(36) & & 295.87 & & & & \\
\hline MVLB-Qs(24) & & 281.85 & & & & \\
\hline MVLB-Qs(36) & & 377.40 & & & & \\
\hline
\end{tabular}

Note: See note for Table A1-1. 
Table A1-3: Full sample estimation results - India

\begin{tabular}{|c|c|c|c|c|c|c|}
\hline \multirow[b]{2}{*}{$\mathbf{R}_{\mathrm{i1}}(\mathbf{1})$} & \multicolumn{2}{|c|}{ USA(i=1) } & \multicolumn{2}{|c|}{ JPN(i=2) } & \multicolumn{2}{|c|}{ IND(i=3) } \\
\hline & -0.0158 & $(0.0148)$ & $0.4408 * * *$ & $(0.0121)$ & $0.2094 * * *$ & $(0.0146)$ \\
\hline $\mathbf{R}_{\mathrm{i} 1}(2)$ & -0.0160 & $(0.0127)$ & $0.0583^{* * *}$ & $(0.0119)$ & $0.0774 * * *$ & $(0.0124)$ \\
\hline $\mathbf{R}_{\mathrm{i1}}(3)$ & $-0.0488 * * *$ & $(0.0140)$ & 0.0009 & $(0.0110)$ & $0.0477 * * *$ & $(0.0125)$ \\
\hline $\mathbf{R}_{\mathrm{i1}}(4)$ & -0.0170 & $(0.0138)$ & $0.0249 * *$ & $(0.0110)$ & $0.0397 * * *$ & $(0.0128)$ \\
\hline $\mathbf{R}_{\mathrm{i} 2}(\mathbf{1})$ & -0.0079 & $(0.0088)$ & -0.0129 & $(0.0110)$ & $-0.0450 * * *$ & $(0.0111)$ \\
\hline $\mathbf{R}_{\mathrm{i} 2}(2)$ & $0.0192^{* *}$ & $(0.0098)$ & 0.0114 & $(0.0097)$ & 0.0048 & $(0.0094)$ \\
\hline $\mathbf{R}_{\mathrm{i} 2}(\mathbf{3})$ & 0.0109 & $(0.0090)$ & -0.0146 & $(0.0100)$ & $0.0258^{* *}$ & $(0.0110)$ \\
\hline $\mathbf{R}_{\mathrm{i} 2}(4)$ & $-0.0298 * * *$ & $(0.0084)$ & -0.0020 & $(0.0083)$ & 0.0012 & (0.0113) \\
\hline $\mathbf{R}_{\mathrm{i3}}(\mathbf{1})$ & 0.0004 & $(0.0072)$ & $0.0381^{* * *}$ & $(0.0085)$ & $0.0613^{* * *}$ & $(0.0114)$ \\
\hline $\mathbf{R}_{\mathrm{i3}}(2)$ & $0.0246 * * *$ & $(0.0069)$ & -0.0093 & $(0.0075)$ & -0.0036 & $(0.0111)$ \\
\hline $\mathbf{R}_{\mathrm{i} 3}(\mathbf{3})$ & -0.0121 & $(0.0078)$ & 0.0048 & $(0.0082)$ & $-0.0192 *$ & (0.0111) \\
\hline $\mathbf{R}_{\mathrm{i} 3}(4)$ & 0.0020 & $(0.0077)$ & 0.0022 & $(0.0079)$ & $0.0278^{* * *}$ & $(0.0100)$ \\
\hline Constant & $0.0366^{* * *}$ & $(0.0105)$ & -0.0105 & $(0.0148)$ & $0.0538 * * *$ & $(0.0145)$ \\
\hline$C(\mathbf{i}, \mathbf{1})$ & $0.0995 * * *$ & $(0.0086)$ & -0.0049 & $(0.0223)$ & 0.0134 & $(0.0243)$ \\
\hline$C(\mathbf{i}, 2)$ & & & $0.2014 * * *$ & $(0.0170)$ & $0.0914 * * *$ & $(0.0208)$ \\
\hline$C(\mathbf{i}, 3)$ & & & & & $0.1603 * * *$ & $(0.0204)$ \\
\hline$A(\mathbf{i}, 1)$ & $0.0336^{*}$ & $(0.0185)$ & $-0.0329 * * *$ & $(0.0086)$ & $0.0274 * * *$ & $(0.0066)$ \\
\hline$A(i, 2)$ & $0.1656^{* * *}$ & $(0.0127)$ & $0.1601^{* * *}$ & $(0.0163)$ & -0.0108 & (0.0079) \\
\hline$A(\mathbf{i}, 3)$ & $0.0941 * * *$ & $(0.0138)$ & -0.0074 & $(0.0169)$ & $0.2491 * * *$ & $(0.0130)$ \\
\hline G (i,1) & $0.9647 * * *$ & $(0.0030)$ & $0.0082^{* *}$ & $(0.0038)$ & $-0.0078 * * *$ & $(0.0023)$ \\
\hline $\mathbf{G}(\mathbf{i}, 2)$ & 0.0006 & $(0.0043)$ & $0.9352 * * *$ & $(0.0064)$ & -0.0027 & $(0.0034)$ \\
\hline G (i,3) & $0.0107 * *$ & $(0.0048)$ & $-0.0364 * * *$ & $(0.0072)$ & $0.9500 * * *$ & $(0.0042)$ \\
\hline$D(\mathbf{i}, \mathbf{1})$ & $0.3485^{* * *}$ & $(0.0153)$ & -0.0203 & $(0.0130)$ & $-0.0213^{* *}$ & $(0.0103)$ \\
\hline$D(\mathbf{i}, 2)$ & -0.0105 & $(0.0238)$ & $0.2972 * * *$ & $(0.0219)$ & $-0.1139 * * *$ & $(0.0166)$ \\
\hline$D(\mathbf{i}, 3)$ & $0.0722^{* * *}$ & $(0.0237)$ & $0.1073^{* * *}$ & $(0.0239)$ & $-0.2263 * * *$ & $(0.0238)$ \\
\hline MVLB-Q(24) & & 207.70 & & & & \\
\hline MVLB-Q(36) & & 320.87 & & & & \\
\hline MVLB-Qs(24) & & 238.89 & & & & \\
\hline MVLB-Qs(36) & & 337.53 & & & & \\
\hline
\end{tabular}

Note: See note for Table A1-1. 
Table A1-4: Full sample estimation results - Malaysia

\begin{tabular}{|c|c|c|c|c|c|c|}
\hline \multirow[b]{2}{*}{$\mathbf{R}_{\mathbf{i 1}}(\mathbf{1})$} & \multicolumn{2}{|c|}{ USA(i=1) } & \multicolumn{2}{|c|}{$\operatorname{JPN}(i=2)$} & \multicolumn{2}{|c|}{$\operatorname{MYS}(\mathbf{i}=3)$} \\
\hline & -0.0125 & $(0.0131)$ & $0.4368 * * *$ & $(0.0104)$ & $0.1977 * * *$ & $(0.0086)$ \\
\hline $\mathbf{R}_{\mathrm{i1}}(\mathbf{2})$ & -0.0098 & $(0.0104)$ & $0.0554^{* * *}$ & $(0.0096)$ & 0.0178* & $(0.0102)$ \\
\hline $\mathbf{R}_{\mathrm{i1}}(\mathbf{3})$ & $-0.0336 * * *$ & $(0.0108)$ & 0.0064 & $(0.0111)$ & $0.0344 * * *$ & $(0.0092)$ \\
\hline $\mathbf{R}_{\mathbf{i 1}}(4)$ & $-0.0180 *$ & $(0.0105)$ & $0.0251^{* *}$ & $(0.0107)$ & 0.0179* & $(0.0093)$ \\
\hline $\mathbf{R}_{\mathrm{i} 2}(\mathbf{1})$ & -0.0054 & $(0.0077)$ & -0.0013 & $(0.0106)$ & $-0.0144 *$ & $(0.0082)$ \\
\hline $\mathbf{R}_{\mathrm{i} 2}(2)$ & $0.0216^{* *}$ & $(0.0090)$ & 0.0064 & $(0.0097)$ & -0.0021 & $(0.0086)$ \\
\hline $\mathbf{R}_{\mathrm{i} 2}(\mathbf{3})$ & 0.0070 & $(0.0089)$ & -0.0156 & $(0.0095)$ & 0.0081 & $(0.0083)$ \\
\hline $\mathbf{R}_{\mathrm{i} 2}(4)$ & $-0.0237 * * *$ & $(0.0086)$ & 0.0028 & $(0.0087)$ & 0.0126 & $(0.0092)$ \\
\hline $\mathbf{R}_{\mathrm{i3}}(\mathbf{1})$ & -0.0063 & $(0.0060)$ & 0.0132 & $(0.0093)$ & $0.1281^{* * *}$ & $(0.0118)$ \\
\hline $\mathbf{R}_{\mathrm{i3}}(2)$ & $-0.0178 * *$ & $(0.0072)$ & -0.0046 & $(0.0089)$ & 0.0028 & $(0.0086)$ \\
\hline $\mathbf{R}_{\mathrm{i} 3}(\mathbf{3})$ & 0.0104 & $(0.0078)$ & 0.0076 & $(0.0088)$ & $0.0306^{* * *}$ & $(0.0096)$ \\
\hline $\mathbf{R}_{\mathrm{i3}}(4)$ & $-0.0137 *$ & $(0.0082)$ & -0.0082 & $(0.0090)$ & $-0.0312 * * *$ & $(0.0079)$ \\
\hline Constant & $0.0361^{* * *}$ & $(0.0115)$ & -0.0069 & $(0.0137)$ & $0.0285^{* * *}$ & (0.0099) \\
\hline$C(\mathbf{i}, \mathbf{1})$ & $0.1099 * * *$ & $(0.0070)$ & $-0.0353^{* *}$ & $(0.0162)$ & -0.0087 & (0.0089) \\
\hline$C(\mathbf{i}, 2)$ & & & $0.2238 * * *$ & $(0.0189)$ & $0.0371 * * *$ & $(0.0094)$ \\
\hline$C(\mathbf{i}, 3)$ & & & & & $0.0654 * * *$ & (0.0079) \\
\hline$A(\mathbf{i}, \mathbf{1})$ & 0.0046 & $(0.0171)$ & -0.0063 & $(0.0076)$ & 0.0034 & $(0.0042)$ \\
\hline$A(i, 2)$ & $0.1547^{* * *}$ & $(0.0134)$ & $0.1805^{* * *}$ & $(0.0153)$ & $0.0290 * *$ & $(0.0144)$ \\
\hline$A(i, 3)$ & $0.0400^{* * *}$ & $(0.0072)$ & 0.0035 & $(0.0084)$ & $0.2681^{* * *}$ & $(0.0150)$ \\
\hline G (i,1) & $0.9625^{* * *}$ & $(0.0025)$ & $0.0080 * *$ & $(0.0037)$ & $0.0032^{* *}$ & $(0.0014)$ \\
\hline $\mathbf{G}(\mathbf{i}, 2)$ & 0.0046 & $(0.0046)$ & $0.9248 * * *$ & $(0.0074)$ & -0.0014 & $(0.0029)$ \\
\hline G $(\mathbf{i}, 3)$ & $0.0041^{*}$ & $(0.0022)$ & $-0.0135^{* * *}$ & $(0.0038)$ & $0.9569 * * *$ & $(0.0033)$ \\
\hline$D(\mathbf{i}, \mathbf{1})$ & $-0.3552 * * *$ & $(0.0140)$ & $0.0354 * * *$ & $(0.0112)$ & 0.0073 & $(0.0102)$ \\
\hline$D(\mathbf{i}, 2)$ & $0.0420 *$ & $(0.0220)$ & $-0.2969 * * *$ & $(0.0220)$ & 0.0062 & $(0.0385)$ \\
\hline D (i,3) & -0.0156 & $(0.0117)$ & $-0.0550 * * *$ & $(0.0130)$ & $0.1811 * * *$ & $(0.0283)$ \\
\hline MVLB-Q(24) & & 190.48 & & & & \\
\hline MVLB-Q(36) & & 290.98 & & & & \\
\hline MVLB-Qs(24) & & 211.73 & & & & \\
\hline MVLB-Qs(36) & & 336.55 & & & & \\
\hline
\end{tabular}

Note: See note for Table A1-1. 
Table A1-5: Full sample estimation results - Philippines

\begin{tabular}{|c|c|c|c|c|c|c|}
\hline \multirow[b]{2}{*}{$\mathbf{R}_{\mathbf{i 1}}(\mathbf{1})$} & \multicolumn{2}{|c|}{ USA(i=1) } & \multicolumn{2}{|c|}{$\operatorname{JPN}(\mathbf{i}=2)$} & \multicolumn{2}{|c|}{ PHL(i=3) } \\
\hline & -0.0109 & $(0.0148)$ & $0.4371^{* * *}$ & $(0.0138)$ & $0.3798^{* * *}$ & $(0.0141)$ \\
\hline$R_{i 1}(2)$ & -0.0112 & $(0.0128)$ & $0.0604 * * *$ & $(0.0122)$ & $-0.0245^{*}$ & $(0.0134)$ \\
\hline $\mathbf{R}_{\mathrm{i1}}(\mathbf{3})$ & $-0.0361^{* * *}$ & $(0.0133)$ & 0.0022 & $(0.0116)$ & $0.0316^{* *}$ & $(0.0132)$ \\
\hline $\mathbf{R}_{\mathrm{i1}}(\mathbf{4})$ & -0.0201 & $(0.0132)$ & $0.0256^{* *}$ & $(0.0125)$ & -0.0078 & $(0.0135)$ \\
\hline $\mathbf{R}_{\mathrm{i} 2}(\mathbf{1})$ & -0.0127 & $(0.0083)$ & -0.0110 & $(0.0126)$ & $0.0271^{* *}$ & $(0.0113)$ \\
\hline $\mathbf{R}_{\mathrm{i} 2}(\mathbf{2})$ & $0.0194 * *$ & $(0.0092)$ & 0.0011 & $(0.0106)$ & -0.0011 & $(0.0112)$ \\
\hline $\mathbf{R}_{\mathrm{i} 2}(\mathbf{3})$ & $0.0146 *$ & $(0.0081)$ & -0.0098 & $(0.0115)$ & 0.0188* & $(0.0104)$ \\
\hline $\mathbf{R}_{\mathrm{i} 2}(\mathbf{4})$ & $-0.0226 * * *$ & $(0.0081)$ & 0.0085 & $(0.0098)$ & -0.0092 & $(0.0122)$ \\
\hline$R_{\mathrm{i} 3}(\mathbf{1})$ & 0.0010 & (0.0073) & -0.0009 & $(0.0102)$ & $0.1463^{* * *}$ & $(0.0119)$ \\
\hline $\mathbf{R}_{\mathrm{i3}}(2)$ & -0.0020 & $(0.0079)$ & 0.0069 & $(0.0090)$ & -0.0053 & $(0.0117)$ \\
\hline $\mathbf{R}_{\mathrm{i} 3}(\mathbf{3})$ & -0.0065 & (0.0073) & $-0.0224 * *$ & $(0.0101)$ & -0.0117 & $(0.0106)$ \\
\hline $\mathbf{R}_{\mathrm{i3}}(\mathbf{4})$ & $-0.0129 *$ & $(0.0077)$ & $-0.0184^{*}$ & $(0.0101)$ & 0.0095 & $(0.0102)$ \\
\hline Constant & $0.0373 * * *$ & $(0.0096)$ & -0.0044 & $(0.0150)$ & 0.0257 & $(0.0164)$ \\
\hline$C(\mathbf{i}, \mathbf{1})$ & $0.1056^{* * *}$ & $(0.0065)$ & $-0.0289 *$ & $(0.0173)$ & -0.0015 & $(0.0276)$ \\
\hline$C(i, 2)$ & & & $0.1871^{* * *}$ & $(0.0162)$ & 0.0355* & $(0.0203)$ \\
\hline$C(\mathbf{i}, 3)$ & & & & & $0.1964 * * *$ & $(0.0160)$ \\
\hline$A(\mathbf{i}, \mathbf{1})$ & $0.1147 * * *$ & $(0.0166)$ & 0.0032 & $(0.0078)$ & $0.0237 * * *$ & $(0.0077)$ \\
\hline$A(i, 2)$ & $0.1338^{* * *}$ & $(0.0126)$ & $0.1380^{* * *}$ & $(0.0137)$ & $-0.0400 * * *$ & $(0.0100)$ \\
\hline$A(\mathbf{i}, 3)$ & $0.0730 * * *$ & $(0.0166)$ & $0.0346 *$ & $(0.0190)$ & $0.2379 * * *$ & $(0.0148)$ \\
\hline G (i,1) & $0.9604^{* * *}$ & $(0.0027)$ & $0.0086 * * *$ & $(0.0032)$ & -0.0011 & $(0.0038)$ \\
\hline$G(\mathbf{i}, 2)$ & 0.0007 & $(0.0047)$ & $0.9441^{* * *}$ & $(0.0050)$ & 0.0028 & $(0.0047)$ \\
\hline G $(\mathbf{i}, 3)$ & -0.0059 & $(0.0042)$ & $-0.0152 * * *$ & $(0.0052)$ & $0.9430 * * *$ & $(0.0048)$ \\
\hline$D(\mathbf{i}, \mathbf{1})$ & $0.3229 * * *$ & $(0.0128)$ & -0.0110 & $(0.0123)$ & -0.0144 & $(0.0129)$ \\
\hline$D(\mathbf{i}, 2)$ & 0.0297 & $(0.0200)$ & $-0.2802 * * *$ & $(0.0210)$ & -0.0264 & $(0.0171)$ \\
\hline D (i,3) & $0.0434 * *$ & $(0.0209)$ & 0.0115 & $(0.0210)$ & $-0.2636 * * *$ & $(0.0233)$ \\
\hline MVLB-Q(24) & & 195.80 & & & & \\
\hline MVLB-Q(36) & & 293.61 & & & & \\
\hline MVLB-Qs(24) & & 178.35 & & & & \\
\hline MVLB-Qs(36) & & 260.33 & & & & \\
\hline
\end{tabular}

Note: See note for Table A1-1. 
Table A1-6 Full sample estimation results - Thailand

\begin{tabular}{|c|c|c|c|c|c|c|}
\hline \multirow[b]{2}{*}{$\mathbf{R}_{\mathrm{i1}}(\mathbf{1})$} & \multicolumn{2}{|c|}{ USA(i=1) } & \multicolumn{2}{|c|}{ JPN(i=2) } & \multicolumn{2}{|c|}{ THA(i=3) } \\
\hline & $-0.0331^{* *}$ & $(0.0164)$ & $0.4490 * * *$ & (0.0123) & $0.3119^{* * *}$ & $(0.0168)$ \\
\hline$R_{i 1}(2)$ & $-0.0277^{*}$ & $(0.0158)$ & $0.0555^{* * *}$ & $(0.0127)$ & $0.0923^{* * *}$ & $(0.0174)$ \\
\hline $\mathbf{R}_{\mathrm{i} 1}(\mathbf{3})$ & $-0.0438 * * *$ & $(0.0160)$ & 0.0021 & (0.0107) & 0.0333* & (0.0189) \\
\hline$R_{i 1}(4)$ & -0.0103 & $(0.0156)$ & $0.0222 *$ & $(0.0115)$ & 0.0154 & $(0.0162)$ \\
\hline $\mathbf{R}_{\mathrm{i} 2}(\mathbf{1})$ & -0.0060 & $(0.0104)$ & $-0.0242 *$ & $(0.0125)$ & $-0.0300^{*}$ & $(0.0161)$ \\
\hline $\mathbf{R}_{\mathrm{i} 2}(\mathbf{2})$ & 0.0198 & $(0.0121)$ & 0.0064 & (0.0097) & $0.0343^{* *}$ & $(0.0167)$ \\
\hline $\mathbf{R}_{\mathrm{i} 2}(\mathbf{3})$ & 0.0155 & $(0.0115)$ & -0.0021 & $(0.0110)$ & $0.0339 * *$ & $(0.0159)$ \\
\hline $\mathbf{R}_{\mathrm{i} 2}(\mathbf{4})$ & -0.0196 & $(0.0125)$ & 0.0068 & $(0.0102)$ & $0.0363^{* *}$ & $(0.0164)$ \\
\hline $\mathbf{R}_{\mathrm{i3}}(\mathbf{1})$ & $0.0144 *$ & $(0.0078)$ & 0.0141 & $(0.0086)$ & $0.0255^{* *}$ & $(0.0114)$ \\
\hline $\mathbf{R}_{\mathrm{i} 3}(2)$ & 0.0019 & $(0.0081)$ & 0.0063 & $(0.0071)$ & $0.0453^{* * *}$ & $(0.0112)$ \\
\hline $\mathbf{R}_{\mathrm{i} 3}(3)$ & -0.0023 & $(0.0079)$ & -0.0121 & $(0.0081)$ & -0.0153 & $(0.0100)$ \\
\hline $\mathbf{R}_{\mathrm{i} 3}(\mathbf{4})$ & -0.0071 & $(0.0076)$ & -0.0041 & $(0.0075)$ & $-0.0342 * * *$ & $(0.0124)$ \\
\hline Constant & $0.259^{*}$ & $(0.0137)$ & -0.0087 & $(0.0161)$ & 0.0355 & $(0.0231)$ \\
\hline$C(\mathbf{i}, \mathbf{1})$ & $0.1068 * * *$ & $(0.0098)$ & $0.0540 *$ & $(0.0303)$ & $0.1084 * * *$ & $(0.0284)$ \\
\hline$C(i, 2)$ & & & $0.2217 * * *$ & $(0.0184)$ & 0.0070 & $(0.0292)$ \\
\hline$C(\mathbf{i}, 3)$ & & & & & $0.2657 * * *$ & $(0.0182)$ \\
\hline$A(\mathbf{i}, \mathbf{1})$ & $0.0603^{* * *}$ & $(0.0207)$ & 0.0076 & $(0.0136)$ & $0.0246^{* * *}$ & $(0.0063)$ \\
\hline$A(i, 2)$ & $-0.1242 * * *$ & $(0.0163)$ & $-0.1145^{* * *}$ & $(0.0227)$ & -0.0129 & $(0.0084)$ \\
\hline$A(i, 3)$ & $-0.1250 * * *$ & $(0.0177)$ & -0.0019 & $(0.0191)$ & $0.2333^{* * *}$ & $(0.0149)$ \\
\hline G (i,1) & $0.9669 * * *$ & $(0.0029)$ & -0.0010 & $(0.0056)$ & $-0.0145 * * *$ & $(0.0023)$ \\
\hline G (i,2) & -0.0003 & $(0.0042)$ & $0.9293 * * *$ & $(0.0068)$ & 0.0048 & $(0.0038)$ \\
\hline G $(\mathbf{i}, 3)$ & 0.0019 & $(0.0043)$ & -0.0130 & $(0.0083)$ & $0.9404 * * *$ & $(0.0054)$ \\
\hline D (i,1) & $0.3264 * * *$ & $(0.0156)$ & -0.0244 & $(0.0154)$ & $0.0184^{* *}$ & $(0.0087)$ \\
\hline$D(i, 2)$ & $0.0478 * *$ & (0.0229) & $0.3115^{* * *}$ & $(0.0210)$ & 0.0071 & $(0.0114)$ \\
\hline D $(\mathbf{i}, 3)$ & 0.0322 & $(0.0246)$ & 0.0029 & $(0.0243)$ & $0.2692^{* * *}$ & $(0.0255)$ \\
\hline MVLB-Q(24) & & 214.56 & 9) & & & \\
\hline MVLB-Q(36) & & 305.42 & 37) & & & \\
\hline MVLB-Qs(24) & & 170.02 & 09) & & & \\
\hline MVLB-Qs(36) & & 237.01 & 99) & & & \\
\hline
\end{tabular}

Note: See note for Table A1-1. 
Table A2-1: Subsample (Jan 1st, 1997 to Dec 31'st, 2001) estimation results - China

\begin{tabular}{|c|c|c|c|c|c|c|}
\hline \multirow[b]{2}{*}{$\mathbf{R}_{\mathrm{i1}}(\mathbf{1})$} & \multicolumn{2}{|c|}{ USA(i=1) } & \multicolumn{2}{|c|}{ JPN(i=2) } & \multicolumn{2}{|c|}{$\mathrm{CHN}(\mathrm{i}=3)$} \\
\hline & $0.0519 *$ & $(0.0281)$ & $0.3706^{* * *}$ & $(0.0218)$ & 0.0005 & $(0.0240)$ \\
\hline $\mathbf{R}_{\mathrm{i1}}(\mathbf{2})$ & -0.0063 & $(0.0261)$ & 0.0121 & $(0.0258)$ & -0.0305 & $(0.0236)$ \\
\hline $\mathbf{R}_{\mathrm{i} 2}(\mathbf{1})$ & -0.0282 & $(0.0194)$ & 0.0209 & $(0.0263)$ & 0.0283 & $(0.0240)$ \\
\hline $\mathbf{R}_{\mathrm{i} 2}(2)$ & -0.0137 & $(0.0202)$ & -0.0210 & (0.0209) & -0.0343 & $(0.0237)$ \\
\hline $\mathbf{R}_{\mathrm{i} 3}(\mathbf{1})$ & -0.0247 & $(0.0187)$ & -0.0113 & $(0.0208)$ & 0.0023 & $(0.0293)$ \\
\hline $\mathbf{R}_{\mathrm{i} 3}(2)$ & 0.0247 & $(0.0202)$ & -0.0046 & (0.0197) & -0.0125 & $(0.0273)$ \\
\hline Constant & 0.0168 & $(0.0317)$ & -0.0496 & $(0.0322)$ & 0.0413 & $(0.0308)$ \\
\hline$C(\mathbf{i}, \mathbf{1})$ & $0.2812^{* * *}$ & $(0.0324)$ & $-0.1003^{*}$ & $(0.0515)$ & $-0.3176^{* * *}$ & $(0.0857)$ \\
\hline$C(\mathbf{i}, 2)$ & & & $0.2009 * * *$ & $(0.0435)$ & -0.1151 & $(0.1463)$ \\
\hline$C(\mathbf{i}, 3)$ & & & & & $0.4016^{* * *}$ & $(0.0923)$ \\
\hline$A(\mathbf{i}, \mathbf{1})$ & 0.0110 & $(0.0364)$ & 0.0392 & $(0.0347)$ & 0.0086 & $(0.0203)$ \\
\hline$A(i, 2)$ & $-0.1724 * * *$ & $(0.0249)$ & $-0.0925 * * *$ & $(0.0329)$ & 0.0035 & $(0.0227)$ \\
\hline A $(\mathbf{i}, 3)$ & -0.0294 & $(0.0425)$ & $0.0741 * *$ & $(0.0337)$ & $0.4290 * * *$ & $(0.0438)$ \\
\hline G (i,1) & $0.9165^{* * *}$ & $(0.0118)$ & $0.0508^{* * *}$ & $(0.0131)$ & 0.0037 & $(0.0135)$ \\
\hline$G(\mathbf{i}, 2)$ & -0.0066 & $(0.0156)$ & $0.9459 * * *$ & $(0.0124)$ & 0.0009 & $(0.0131)$ \\
\hline G $(\mathbf{i}, 3)$ & $0.0877^{* * *}$ & $(0.0190)$ & -0.0173 & $(0.0219)$ & $0.8049 * * *$ & $(0.0272)$ \\
\hline$D(\mathbf{i}, \mathbf{1})$ & $-0.4452 * * *$ & $(0.0386)$ & -0.0126 & $(0.0394)$ & 0.0184 & $(0.0240)$ \\
\hline$D(\mathbf{i}, 2)$ & $-0.0941^{* *}$ & $(0.0426)$ & $0.2753^{* * *}$ & $(0.0369)$ & 0.0143 & $(0.0277)$ \\
\hline$D(\mathbf{i}, 3)$ & $0.2243^{* * *}$ & $(0.0604)$ & $-0.0997^{*}$ & $(0.0537)$ & $0.3206^{* * *}$ & $(0.0676)$ \\
\hline MVLB-Q(24) & & 250.08 & & & & \\
\hline MVLB-Q(36) & & 359.02 & & & & \\
\hline MVLB-Qs(24) & & 209.27 & & & & \\
\hline MVLB-Qs(36) & & 367.03 & 98) & & & \\
\hline
\end{tabular}

Note: See note for Table A1-1. 
Table A2-2: Subsample (Jan 1 ${ }^{\text {st }}, 1997$ to Dec 31st, 2001) estimation results - Indonesia

\begin{tabular}{|c|c|c|c|c|c|c|}
\hline \multirow[b]{2}{*}{$\mathbf{R}_{\mathrm{i1}}(\mathbf{1})$} & \multicolumn{2}{|c|}{ USA(i=1) } & \multicolumn{2}{|c|}{$J P N(i=2)$} & \multicolumn{2}{|c|}{$\operatorname{IDN}(\mathrm{i}=3)$} \\
\hline & 0.0352* & $(0.0209)$ & $0.3724 * * *$ & (0.0229) & $0.2580^{* * *}$ & $(0.0293)$ \\
\hline $\mathbf{R}_{\mathrm{i} 1}(2)$ & -0.0086 & $(0.0238)$ & 0.0361 & (0.0259) & -0.0025 & $(0.0313)$ \\
\hline $\mathbf{R}_{\mathrm{i} 2}(\mathbf{1})$ & -0.0241 & $(0.0219)$ & 0.0361 & $(0.0244)$ & -0.0434 & $(0.0346)$ \\
\hline $\mathbf{R}_{\mathrm{i} 2}(2)$ & -0.0083 & $(0.0219)$ & -0.0316 & $(0.0217)$ & 0.0079 & $(0.0333)$ \\
\hline $\mathbf{R}_{\mathrm{i} 3}(\mathbf{1})$ & 0.0197 & $(0.0137)$ & 0.0112 & $(0.0157)$ & $0.1738^{* * *}$ & $(0.0229)$ \\
\hline $\mathbf{R}_{\mathrm{i} 3}(\mathbf{2})$ & -0.0236 & $(0.0158)$ & 0.0020 & $(0.0150)$ & 0.0252 & $(0.0237)$ \\
\hline Constant & 0.0106 & $(0.0287)$ & $-0.0585^{*}$ & $(0.0335)$ & -0.0546 & $(0.0380)$ \\
\hline$C(\mathbf{i}, \mathbf{1})$ & $0.4197 * * *$ & $(0.0767)$ & -0.0403 & $(0.1296)$ & $0.1448^{* * *}$ & $(0.0434)$ \\
\hline$C(\mathbf{i}, 2)$ & & & 0.1270 & $(0.2632)$ & 0.0258 & $(0.2582)$ \\
\hline$C(\mathbf{i}, 3)$ & & & & & 1.3E-05 & $(0.3502)$ \\
\hline$A(\mathbf{i}, \mathbf{1})$ & -0.0084 & $(0.0357)$ & $-0.1910^{* * *}$ & $(0.0325)$ & 0.0172 & $(0.0151)$ \\
\hline$A(i, 2)$ & $0.1519 * * *$ & $(0.0401)$ & $-0.0882 * *$ & $(0.0440)$ & -0.0030 & $(0.0157)$ \\
\hline$A(\mathbf{i}, 3)$ & 0.0594 & $(0.0361)$ & -0.0021 & $(0.0448)$ & $0.2609 * * *$ & $(0.0290)$ \\
\hline G (i,1) & $0.7790 * * *$ & $(0.0336)$ & $0.2641 * * *$ & $(0.0300)$ & 0.0024 & $(0.0098)$ \\
\hline$G(\mathbf{i}, 2)$ & $-0.3009 * * *$ & $(0.0405)$ & $0.9552 * * *$ & $(0.0272)$ & $0.0171^{* *}$ & $(0.0084)$ \\
\hline G (i,3) & $-0.0696 * *$ & $(0.0348)$ & $-0.0440 *$ & $(0.0234)$ & $0.9552 * * *$ & $(0.0081)$ \\
\hline$D(\mathbf{i}, \mathbf{1})$ & $0.4364 * * *$ & $(0.0453)$ & 0.0986* & $(0.0507)$ & 0.0284 & $(0.0234)$ \\
\hline$D(\mathbf{i}, 2)$ & $0.1459 * * *$ & $(0.0556)$ & $-0.1754 * * *$ & $(0.0497)$ & -0.0058 & $(0.0258)$ \\
\hline$D(\mathbf{i}, 3)$ & 0.0229 & $(0.0569)$ & -0.0355 & $(0.0527)$ & $-0.2161 * * *$ & $(0.0462)$ \\
\hline MVLB-Q(24) & & 248.09 & 61) & & & \\
\hline MVLB-Q(36) & & 338.44 & 93) & & & \\
\hline MVLB-Qs(24) & & 248.65 & 30) & & & \\
\hline MVLB-Qs(36) & & 361.41 & 46) & & & \\
\hline
\end{tabular}

Note: See note for Table A1-1. 
Table A2-3: Subsample (Jan 1 ${ }^{\text {st }}, 1997$ to Dec 31'st, 2001) estimation results - India

\begin{tabular}{|c|c|c|c|c|c|c|}
\hline \multirow[b]{2}{*}{$\mathbf{R}_{\mathbf{i 1}}(\mathbf{1})$} & \multicolumn{2}{|c|}{ USA(i=1) } & \multicolumn{2}{|c|}{ JPN(i=2) } & \multicolumn{2}{|c|}{$\operatorname{IND}(\mathrm{i}=3)$} \\
\hline & 0.0247 & $(0.0277)$ & $0.3762 * * *$ & $(0.0234)$ & $0.1857 * * *$ & $(0.0388)$ \\
\hline $\mathbf{R}_{\mathrm{i} 1}(2)$ & -0.0265 & $(0.0272)$ & 0.0346 & $(0.0281)$ & 0.0518 & $(0.0382)$ \\
\hline $\mathbf{R}_{\mathrm{i} 2}(\mathbf{1})$ & -0.0234 & $(0.0248)$ & 0.0208 & $(0.0265)$ & $-0.0860 * *$ & $(0.0364)$ \\
\hline $\mathbf{R}_{\mathrm{i} 2}(\mathbf{2})$ & -0.0268 & $(0.0219)$ & -0.0342 & $(0.0229)$ & 0.0307 & $(0.0328)$ \\
\hline $\mathbf{R}_{\mathrm{i3}}(\mathbf{1})$ & -0.0224 & $(0.0167)$ & 0.0020 & $(0.0166)$ & $0.0756 * * *$ & $(0.0281)$ \\
\hline $\mathbf{R}_{\mathrm{i3}}(2)$ & $0.0315^{*}$ & $(0.0174)$ & 0.0115 & $(0.0133)$ & 0.0393 & $(0.0254)$ \\
\hline Constant & 0.0380 & $(0.0332)$ & $-0.0524 *$ & $(0.0307)$ & -0.0011 & $(0.0487)$ \\
\hline$C(\mathbf{i}, \mathbf{1})$ & $0.3929 * * *$ & $(0.0923)$ & 0.1675 & $(0.1484)$ & -0.2077 & $(0.2232)$ \\
\hline$C(\mathbf{i}, 2)$ & & & 0.1762 & $(0.2000)$ & -0.0935 & $(0.4997)$ \\
\hline$C(\mathbf{i}, 3)$ & & & & & $0.5785 * * *$ & $(0.1915)$ \\
\hline$A(\mathbf{i}, 1)$ & 0.0277 & $(0.0452)$ & $0.1182^{* * *}$ & $(0.0414)$ & -0.0196 & $(0.0269)$ \\
\hline$A(i, 2)$ & $0.1816^{* * *}$ & $(0.0347)$ & -0.0400 & $(0.0581)$ & -0.0103 & $(0.0247)$ \\
\hline A (i,3) & $0.1425^{* * *}$ & $(0.0536)$ & $0.1690^{* * *}$ & (0.0569) & $0.1861 * * *$ & $(0.0471)$ \\
\hline G (i,1) & $0.7628 * * *$ & $(0.0353)$ & $0.2288^{* * *}$ & $(0.0351)$ & $0.1523 * * *$ & $(0.0038)$ \\
\hline$G(i, 2)$ & $-0.3462 * * *$ & $(0.0419)$ & $0.9224 * * *$ & $(0.0277)$ & 0.0372 & $(0.0301)$ \\
\hline G $(\mathbf{i}, 3)$ & $-0.2658 * * *$ & $(0.0622)$ & -0.0535 & $(0.0438)$ & $0.8684 * * *$ & $(0.0406)$ \\
\hline$D(\mathbf{i}, \mathbf{1})$ & $0.4301 * * *$ & $(0.0438)$ & 0.0836* & $(0.0482)$ & 0.0538 & $(0.0358)$ \\
\hline$D(\mathbf{i}, 2)$ & $0.1600 * * *$ & $(0.0552)$ & $-0.2437 * * *$ & $(0.0524)$ & 0.0292 & $(0.0373)$ \\
\hline$D(i, 3)$ & 0.1011 & $(0.0731)$ & $0.1654^{* *}$ & $(0.0722)$ & -0.3279 & $(0.0678)$ \\
\hline MVLB-Q(24) & & 240.60 & 04) & & & \\
\hline MVLB-Q(36) & & 336.10 & 1) & & & \\
\hline MVLB-Qs(24) & & 235.50 & 28) & & & \\
\hline MVLB-Qs(36) & & 354.53 & 71) & & & \\
\hline
\end{tabular}

Note: See note for Table A1-1. 
Table A2-4: Subsample (Jan 1'st, 1997 to Dec 31'st, 2001) estimation results - Malaysia

\begin{tabular}{|c|c|c|c|c|c|c|}
\hline \multirow[b]{2}{*}{$\mathbf{R}_{\mathrm{i} 1}(\mathbf{1})$} & \multicolumn{2}{|c|}{ USA(i=1) } & \multicolumn{2}{|c|}{$\operatorname{JPN}(i=2)$} & \multicolumn{2}{|c|}{ MYS(i=3) } \\
\hline & $0.0467^{*}$ & $(0.0258)$ & $0.3343^{* * *}$ & $(0.0251)$ & $0.2006^{* * *}$ & $(0.0292)$ \\
\hline $\mathbf{R}_{\mathrm{i1}}(\mathbf{2})$ & -0.0164 & $(0.0253)$ & 0.0370 & $(0.0266)$ & 0.0357 & $(0.0310)$ \\
\hline $\mathbf{R}_{\mathrm{i} 2}(\mathbf{1})$ & -0.0242 & $(0.0236)$ & 0.0338 & $(0.0243)$ & $-0.0646^{* * *}$ & $(0.0238)$ \\
\hline$R_{\mathrm{i} 2}(2)$ & -0.0093 & $(0.0098)$ & $-0.0454 * *$ & $(0.0229)$ & 0.0589* & $(0.0304)$ \\
\hline $\mathbf{R}_{\mathrm{i} 3}(\mathbf{1})$ & 0.0108 & $(0.0133)$ & 0.0044 & $(0.0149)$ & $0.1856^{* * *}$ & $(0.0284)$ \\
\hline $\mathbf{R}_{\mathrm{i} 3}(2)$ & 0.0051 & $(0.0131)$ & -0.0058 & $(0.0144)$ & 0.0264 & $(0.0251)$ \\
\hline Constant & 0.0112 & $(0.0305)$ & -0.0396 & $(0.0316)$ & 0.0004 & $(0.0363)$ \\
\hline$C(\mathbf{i}, \mathbf{1})$ & 0.1227 & (0.1373) & $-0.4067 * * *$ & $(0.0650)$ & $-0.1862 * * *$ & $(0.0384)$ \\
\hline$C(\mathbf{i}, 2)$ & & & -0.0010 & $(0.6155)$ & -0.0008 & $(0.0541)$ \\
\hline$C(\mathbf{i}, 3)$ & & & & & $-6.2 \mathrm{E}-06$ & $(0.2848)$ \\
\hline$A(\mathbf{i}, 1)$ & -0.0486 & $(0.0353)$ & $0.0716 *$ & $(0.0417)$ & 0.0032 & $(0.0163)$ \\
\hline$A(i, 2)$ & $-0.1654 * * *$ & $(0.0360)$ & $0.1518^{* * *}$ & $(0.0351)$ & -0.0217 & $(0.0166)$ \\
\hline$A(i, 3)$ & -0.0367 & $(0.0475)$ & 0.0596 & $(0.0427)$ & $0.2886 * * *$ & $(0.0305)$ \\
\hline G (i,1) & $0.7509 * * *$ & $(0.0246)$ & $-0.6934 * * *$ & $(0.0333)$ & $0.0374 * *$ & $(0.0170)$ \\
\hline G $(\mathbf{i}, 2)$ & $0.7039 * * *$ & $(0.0318)$ & $0.4761^{* * *}$ & $(0.0342)$ & 0.0353* & $(0.0180)$ \\
\hline G (i,3) & 0.0345 & $(0.0341)$ & $-0.1133 * * *$ & $(0.0153)$ & $0.9403^{* * *}$ & $(0.0067)$ \\
\hline D (i,1) & $-0.2501 * * *$ & $(0.0421)$ & $-0.1250 * * *$ & $(0.0471)$ & 0.0440 & (0.0285) \\
\hline$D(\mathbf{i}, 2)$ & $0.2079 * * *$ & $(0.0435)$ & $0.1822^{* * *}$ & $(0.0483)$ & 0.0426 & $(0.0274)$ \\
\hline$D(\mathbf{i}, 3)$ & $0.1293 * * *$ & $(0.0336)$ & $-0.1976 * * *$ & $(0.0362)$ & $0.2949 * * *$ & (0.0495) \\
\hline MVLB-Q(24) & & 244.91 & 62) & & & \\
\hline MVLB-Q(36) & & 229.45 & 4) & & & \\
\hline MVLB-Qs(24) & & 217.16 & 51) & & & \\
\hline MVLB-Qs(36) & & 306.66 & 78) & & & \\
\hline
\end{tabular}

Note: See note for Table A1-1. 
Table A2-5: Subsample (Jan 1st, 1997 to Dec 31st, 2001) estimation results - Philippines

\begin{tabular}{|c|c|c|c|c|c|c|}
\hline \multirow[b]{2}{*}{$\mathbf{R}_{\mathrm{i1}}(\mathbf{1})$} & \multicolumn{2}{|c|}{ USA(i=1) } & \multicolumn{2}{|c|}{ JPN(i=2) } & \multicolumn{2}{|c|}{ PHL(i=3) } \\
\hline & 0.0332 & $(0.0261)$ & $0.3681^{* * *}$ & $(0.0263)$ & $0.2892 * * *$ & $(0.0336)$ \\
\hline $\mathbf{R}_{\mathrm{i1}}(2)$ & 0.0042 & $(0.0271)$ & $0.0519 * * *$ & $(0.0140)$ & $0.0761^{* *}$ & $(0.0334)$ \\
\hline$R_{\mathrm{i} 2}(\mathbf{1})$ & -0.0316 & $(0.0245)$ & 0.0283 & $(0.0230)$ & -0.0372 & $(0.0310)$ \\
\hline $\mathbf{R}_{\mathrm{i} 2}(2)$ & $-0.0410 *$ & $(0.0232)$ & $-0.0445^{* *}$ & $(0.0207)$ & -0.0039 & $(0.0289)$ \\
\hline$R_{\mathrm{i} 3}(\mathbf{1})$ & 0.0026 & $(0.0168)$ & -0.0002 & $(0.0181)$ & $0.1371 * * *$ & (0.0279) \\
\hline $\mathbf{R}_{\mathrm{i} 3}(2)$ & 0.0126 & $(0.0162)$ & 0.0052 & $(0.0149)$ & -0.0008 & $(0.0280)$ \\
\hline Constant & 0.0147 & $(0.0323)$ & -0.0473 & (0.0294) & $-0.1132 * * *$ & $(0.0376)$ \\
\hline$C(\mathbf{i}, \mathbf{1})$ & $0.5229 * * *$ & $(0.0431)$ & 0.0336 & $(0.0945)$ & $0.2661 * * *$ & $(0.0641)$ \\
\hline$C(\mathbf{i}, 2)$ & & & $-1.3 \mathrm{E}-05$ & $(0.2693)$ & -8.9E-06 & $(0.2063)$ \\
\hline$C(\mathbf{i}, 3)$ & & & & & $-4.2 \mathrm{E}-06$ & $(0.0725)$ \\
\hline$A(i, 1)$ & $0.1225^{* * *}$ & $(0.0461)$ & $0.1526 * * *$ & $(0.0348)$ & $0.0562 * *$ & (0.0246) \\
\hline$A(i, 2)$ & $-0.2358 * * *$ & $(0.0338)$ & 0.0454 & $(0.0317)$ & 0.0031 & (0.0219) \\
\hline$A(\mathbf{i}, 3)$ & -0.0190 & $(0.0422)$ & 0.0467 & $(0.0386)$ & $0.2189 * * *$ & $(0.0374)$ \\
\hline G (i,1) & $0.7633^{* * *}$ & $(0.0256)$ & $0.1929 * * *$ & $(0.0248)$ & $0.0246^{* *}$ & (0.0119) \\
\hline$G(\mathbf{i}, 2)$ & $-0.2114^{* * *}$ & $(0.0358)$ & $0.9629 * * *$ & (0.0089) & $0.0299 * *$ & $(0.0119)$ \\
\hline G (i,3) & $-0.2141^{* * *}$ & $(0.0265)$ & -0.0435 & $(0.0288)$ & $0.9369 * * *$ & $(0.0138)$ \\
\hline D (i,1) & $0.4065 * * *$ & $(0.0486)$ & $0.1334 * * *$ & $(0.0488)$ & -0.0493 & $(0.0334)$ \\
\hline$D(\mathbf{i}, 2)$ & $0.1331 * * *$ & $(0.0494)$ & $-0.1879 * * *$ & $(0.0415)$ & 0.0150 & $(0.0272)$ \\
\hline$D(\mathbf{i}, 3)$ & $0.1853^{* * *}$ & $(0.0523)$ & 0.0276 & (0.0539) & $-0.3930 * * *$ & $(0.0482)$ \\
\hline MVLB-Q(24) & & 218.47 & 01) & & & \\
\hline MVLB-Q(36) & & 218.06 & 26) & & & \\
\hline MVLB-Qs(24) & & 182.87 & 06) & & & \\
\hline MVLB-Qs(36) & & 280.18 & 24) & & & \\
\hline
\end{tabular}

Note: See note for Table A1-1. 
Table A2-6: Subsample (Jan 1st, 1997 to Dec 31'st, 2001) estimation results - Thailand

\begin{tabular}{|c|c|c|c|c|c|c|}
\hline \multirow[b]{2}{*}{$\mathbf{R}_{\mathrm{i} 1}(\mathbf{1})$} & \multicolumn{2}{|c|}{ USA(i=1) } & \multicolumn{2}{|c|}{ JPN(i=2) } & \multicolumn{2}{|c|}{ THA(i=3) } \\
\hline & $0.0394 * *$ & $(0.0180)$ & $0.3519 * * *$ & $(0.0227)$ & $0.3423^{* * *}$ & $(0.0484)$ \\
\hline $\mathbf{R}_{\mathrm{i1}}(\mathbf{2})$ & -0.0146 & $(0.0237)$ & 0.0239 & $(0.0252)$ & 0.0498 & $(0.0514)$ \\
\hline $\mathbf{R}_{\mathrm{i} 2}(\mathbf{1})$ & -0.0104 & $(0.0212)$ & 0.0303 & $(0.0236)$ & 0.0397 & $(0.0440)$ \\
\hline $\mathbf{R}_{\mathrm{i} 2}(\mathbf{2})$ & -0.0301 & $(0.0221)$ & -0.0282 & $(0.0222)$ & 0.0386 & $(0.0486)$ \\
\hline$R_{\mathrm{i} 3}(\mathbf{1})$ & 0.0188* & $(0.0103)$ & 0.0005 & $(0.0123)$ & 0.0499* & $(0.0287)$ \\
\hline $\mathbf{R}_{\mathrm{i3}}(2)$ & 0.0104 & $(0.0123)$ & 0.0024 & $(0.0124)$ & $0.0754^{* * *}$ & $(0.0275)$ \\
\hline Constant & 0.0213 & $(0.0271)$ & -0.0506 & $(0.0330)$ & $-0.1143^{*}$ & $(0.0607)$ \\
\hline$C(\mathbf{i}, 1)$ & $0.3076^{* * *}$ & $(0.0365)$ & -0.0647 & $(0.0523)$ & $-0.2188^{* *}$ & $(0.1067)$ \\
\hline$C(i, 2)$ & & & $0.2047 * * *$ & $(0.0443)$ & 0.1973 & $(0.1512)$ \\
\hline$C(\mathbf{i}, 3)$ & & & & & $0.5515^{* * *}$ & $(0.0955)$ \\
\hline$A(\mathbf{i}, \mathbf{1})$ & 0.0207 & $(0.0353)$ & $-0.0794 * *$ & $(0.0341)$ & 0.0146 & $(0.0127)$ \\
\hline$A(i, 2)$ & $0.1902 * * *$ & $(0.0288)$ & 0.0413 & $(0.0377)$ & 0.0025 & $(0.0148)$ \\
\hline$A(\mathbf{i}, 3)$ & $0.0970 *$ & $(0.0559)$ & 0.0259 & $(0.0495)$ & $0.3163^{* * *}$ & $(0.0298)$ \\
\hline G (i,1) & $0.9121^{* * *}$ & $(0.0157)$ & -0.0099 & $(0.0177)$ & 0.0022 & $(0.0064)$ \\
\hline G $(\mathbf{i}, 2)$ & $0.0511^{* * *}$ & $(0.0197)$ & $0.9421 * * *$ & $(0.0117)$ & -0.0073 & $(0.0084)$ \\
\hline$G(\mathbf{i}, 3)$ & $0.0605^{* *}$ & $(0.0293)$ & -0.0256 & $(0.0327)$ & $0.9043^{* * *}$ & $(0.0156)$ \\
\hline$D(\mathbf{i}, \mathbf{1})$ & $-0.0445^{* * *}$ & $(0.0480)$ & -0.0292 & $(0.0492)$ & -0.0044 & $(0.0166)$ \\
\hline$D(i, 2)$ & $0.1706^{* * *}$ & $(0.0526)$ & $-0.2542^{* * *}$ & $(0.0410)$ & $-0.0308 *$ & $(0.0186)$ \\
\hline$D(\mathbf{i}, 3)$ & 0.1398 & $(0.0852)$ & 0.0765 & $(0.1064)$ & $-0.2056^{* * *}$ & $(0.0678)$ \\
\hline MVLB-Q(24) & & 234.54 & & & & \\
\hline MVLB-Q(36) & & $352.99(0$ & 84) & & & \\
\hline MVLB-Qs(24) & & 216.20 & 34) & & & \\
\hline MVLB-Qs(36) & & 326.23 & 48) & & & \\
\hline
\end{tabular}

Note: See note for Table A1-1. 
Table A3-1: Subsample (Jan 1st, 2008 to Dec 31'st, 2012) estimation results - China

\begin{tabular}{|c|c|c|c|c|c|c|}
\hline \multirow[b]{2}{*}{$R_{\mathrm{i} 1}(\mathbf{1})$} & \multicolumn{2}{|c|}{ USA(i=1) } & \multicolumn{2}{|c|}{ JPN(i=2) } & \multicolumn{2}{|c|}{$\operatorname{CHN}(\mathbf{i}=3)$} \\
\hline & $-0.0670 * *$ & $(0.0308)$ & $0.5891^{* * *}$ & $(0.0188)$ & $0.2444 * * *$ & $(0.0254)$ \\
\hline $\mathbf{R}_{\mathrm{i1}}(2)$ & -0.0298 & $(0.0283)$ & $0.1636^{* * *}$ & $(0.0197)$ & $0.0869 * * *$ & $(0.0232)$ \\
\hline $\mathbf{R}_{\mathrm{i} 2}(\mathbf{1})$ & 0.0114 & $(0.0231)$ & $-0.1377 * * *$ & $(0.0207)$ & $-0.1263^{* * *}$ & $(0.0244)$ \\
\hline $\mathbf{R}_{\mathrm{i} 2}(\mathbf{2})$ & -0.0030 & $(0.0250)$ & -0.0050 & $(0.0166)$ & -0.0091 & $(0.0230)$ \\
\hline $\mathbf{R}_{\mathrm{i} 3}(\mathbf{1})$ & $0.0329 *$ & $(0.0198)$ & $-0.0518^{* * *}$ & $(0.0147)$ & -0.0045 & $(0.0224)$ \\
\hline $\mathbf{R}_{\mathrm{i} 3}(2)$ & -0.0141 & $(0.0197)$ & 0.0047 & $(0.0139)$ & -0.0083 & $(0.0236)$ \\
\hline Constant & 0.0375 & $(0.0288)$ & -0.0278 & $(0.0225)$ & -0.0455 & $(0.0392)$ \\
\hline$C(\mathbf{i}, \mathbf{1})$ & $0.1503^{* * *}$ & $(0.0161)$ & 0.0966 & $(0.0650)$ & $0.1442 * * *$ & $(0.0331)$ \\
\hline$C(i, 2)$ & & & $0.3479 * * *$ & $(0.0387)$ & $0.1236^{* * *}$ & $(0.0365)$ \\
\hline$C(\mathbf{i}, 3)$ & & & & & 0.0436 & $(0.0377)$ \\
\hline$A(\mathbf{i}, \mathbf{1})$ & -0.0326 & $(0.0311)$ & $-0.0509 * *$ & $(0.0213)$ & $0.0353^{* *}$ & $(0.0170)$ \\
\hline$A(i, 2)$ & $0.1711^{* * *}$ & $(0.0291)$ & $0.1547^{* * *}$ & $(0.0321)$ & $0.1114 * * *$ & $(0.0261)$ \\
\hline$A(i, 3)$ & 0.0199 & $(0.0235)$ & 0.0176 & $(0.0221)$ & $0.2011^{* * *}$ & $(0.0192)$ \\
\hline G (i,1) & $0.9510 * * *$ & $(0.0048)$ & 0.0193 & $(0.0141)$ & $-0.0114 * * *$ & $(0.0038)$ \\
\hline G $(\mathbf{i}, \mathbf{2})$ & $-0.0162 *$ & $(0.0094)$ & $0.8263^{* * *}$ & $(0.0236)$ & $-0.0193 * *$ & $(0.0080)$ \\
\hline G (i,3) & $-0.0199 * * *$ & $(0.0055)$ & $-0.0516^{* * *}$ & $(0.0153)$ & $0.9733^{* * *}$ & $(0.0046)$ \\
\hline$D(\mathbf{i}, \mathbf{1})$ & $-0.3962 * * *$ & $(0.0164)$ & 0.0279 & $(0.0321)$ & $0.0648 * *$ & $(0.0279)$ \\
\hline D (i,2) & $-0.1691^{* * *}$ & $(0.0402)$ & $-0.3312 * * *$ & $(0.0445)$ & -0.0421 & $(0.0417)$ \\
\hline$D(\mathbf{i}, 3)$ & $-0.1578 * * *$ & $(0.0272)$ & $-0.0734 * *$ & $(0.0298)$ & 0.0792 & $(0.0482)$ \\
\hline MVLB-Q(24) & & 189.82 & 01) & & & \\
\hline MVLB-Q(36) & & 289.97 & 131) & & & \\
\hline MVLB-Qs(24) & & 233.20 & 009) & & & \\
\hline MVLB-Qs(36) & & 319.89 & 540) & & & \\
\hline
\end{tabular}

Note: See note for Table A1-1. 
Table A3-2: Subsample (Jan 1 ${ }^{\text {st }}, 2008$ to Dec 31st, 2012) estimation results - Indonesia

\begin{tabular}{|c|c|c|c|c|c|c|}
\hline \multirow[b]{2}{*}{$\mathbf{R}_{\mathrm{i1}}(\mathbf{1})$} & \multicolumn{2}{|c|}{ USA(i=1) } & \multicolumn{2}{|c|}{$J P N(i=2)$} & \multicolumn{2}{|c|}{$\operatorname{IDN}(i=3)$} \\
\hline & $-0.0708 * * *$ & $(0.0271)$ & $0.5692 * * *$ & $(0.0188)$ & $0.3805^{* * *}$ & (0.0176) \\
\hline $\mathbf{R}_{\mathrm{i} 1}(\mathbf{2})$ & $-0.0523^{*}$ & $(0.0277)$ & $0.1293 * * *$ & $(0.0238)$ & $0.1046^{* * *}$ & (0.0259) \\
\hline$R_{\mathrm{i} 2}(\mathbf{1})$ & $0.0464 * *$ & $(0.0211)$ & $-0.1276^{* * *}$ & $(0.0231)$ & $-0.0954 * * *$ & (0.0234) \\
\hline $\mathbf{R}_{\mathrm{i} 2}(2)$ & -0.0005 & $(0.0242)$ & 0.0068 & $(0.0225)$ & 0.0307 & (0.0201) \\
\hline $\mathbf{R}_{\mathrm{i3}}(\mathbf{1})$ & 0.0064 & $(0.0236)$ & 0.0027 & $(0.0202)$ & 0.0195 & $(0.0265)$ \\
\hline $\mathbf{R}_{\mathrm{i} 3}(2)$ & -0.0094 & $(0.0229)$ & 0.0025 & $(0.0197)$ & -0.0119 & (0.0253) \\
\hline Constant & 0.0365 & $(0.0271)$ & -0.0385 & $(0.0282)$ & $0.0572^{* *}$ & (0.0259) \\
\hline$C(\mathbf{i}, \mathbf{1})$ & $0.1359 * * *$ & $(0.0225)$ & -0.0006 & $(0.0835)$ & 0.0988 & (0.1027) \\
\hline$C(\mathbf{i}, 2)$ & & & $0.3980 * * *$ & $(0.0428)$ & $0.1771^{* *}$ & (0.0732) \\
\hline$C(\mathbf{i}, 3)$ & & & & & $0.2977 * * *$ & (0.0856) \\
\hline$A(\mathbf{i}, \mathbf{1})$ & -0.0154 & $(0.0333)$ & 0.0101 & $(0.0282)$ & $0.0923 * * *$ & $(0.0232)$ \\
\hline$A(\mathbf{i}, 2)$ & -0.0310 & $(0.0675)$ & 0.0212 & $(0.0882)$ & $-0.0589 *$ & (0.0333) \\
\hline$A(i, 3)$ & $-0.3763 * * *$ & $(0.0436)$ & $-0.1577 * * *$ & $(0.0451)$ & -0.0048 & (0.0398) \\
\hline G (i,1) & $0.9469 * * *$ & $(0.0086)$ & 0.0425 & $(0.0265)$ & 0.0087 & $(0.0227)$ \\
\hline G (i,2) & $-0.0627 * * *$ & $(0.0173)$ & $0.8018 * * *$ & $(0.0333)$ & $0.1824 * * *$ & $(0.0331)$ \\
\hline G (i,3) & 0.0302 & $(0.0246)$ & $-0.2359 * * *$ & $(0.0573)$ & $0.7932 * * *$ & $(0.0455)$ \\
\hline D (i,1) & $-0.3596 * * *$ & $(0.0276)$ & 0.0659* & $(0.0345)$ & -0.0294 & $(0.0344)$ \\
\hline$D(\mathbf{i}, 2)$ & $-0.2002 * * *$ & $(0.0365)$ & $-0.3811^{* * *}$ & $(0.0483)$ & $0.1651^{* * *}$ & $(0.0390)$ \\
\hline D (i,3) & $-0.1139 * *$ & $(0.0573)$ & $-0.1619 * *$ & $(0.0732)$ & $-0.4298 * * *$ & $(0.0492)$ \\
\hline MVLB-Q(24) & & 196.18 & 95) & & & \\
\hline MVLB-Q(36) & & 300.70 & 91) & & & \\
\hline MVLB-Qs(24) & & 225.00 & 31) & & & \\
\hline MVLB-Qs(36) & & 310.87 & 03) & & & \\
\hline
\end{tabular}

Note: See note for Table A1-1. 
Table A3-3: Subsample (Jan 1 ${ }^{\text {st }}, 2008$ to Dec 31'st, 2012) estimation results - India

\begin{tabular}{|c|c|c|c|c|c|c|}
\hline \multirow[b]{2}{*}{$\mathbf{R}_{\mathbf{i} 1}(\mathbf{1})$} & \multicolumn{2}{|c|}{ USA(i=1) } & \multicolumn{2}{|c|}{ JPN(i=2) } & \multicolumn{2}{|c|}{$\operatorname{IND}(\mathbf{i}=3)$} \\
\hline & $-0.0571^{* *}$ & $(0.0289)$ & $0.5585^{* * *}$ & $(0.0203)$ & 0.2935 & $(0.0236)$ \\
\hline $\mathbf{R}_{\mathrm{i} 1}(2)$ & $-0.0519 * *$ & $(0.0256)$ & $0.1453^{* * *}$ & (0.1789) & $0.5585^{* * *}$ & $(0.0203)$ \\
\hline $\mathbf{R}_{\mathrm{i} 2}(\mathbf{1})$ & 0.0166 & $(0.0195)$ & $-0.1513^{* * *}$ & $(0.0220)$ & $0.1453^{* * *}$ & (0.0179) \\
\hline $\mathbf{R}_{\mathrm{i} 2}(2)$ & -0.0102 & $(0.0222)$ & 0.0097 & $(0.0173)$ & $-0.1513^{* * *}$ & $(0.0220)$ \\
\hline $\mathbf{R}_{\mathrm{i} 3}(\mathbf{1})$ & 0.0192 & $(0.0198)$ & $0.0486^{* * *}$ & (0.0169) & 0.0097 & (0.0173) \\
\hline $\mathbf{R}_{\mathrm{i} 3}(2)$ & $0.0387 *$ & $(0.0201)$ & -0.0151 & $(0.0146)$ & $0.0486 * * *$ & (0.0169) \\
\hline Constant & 0.0229 & $(0.0284)$ & -0.0301 & $(0.0253)$ & -0.0151 & $(0.0146)$ \\
\hline$C(\mathbf{i}, 1)$ & $0.1554 * * *$ & $(0.0178)$ & 0.0963* & $(0.0522)$ & 0.0378 & $(0.0315)$ \\
\hline$C(\mathbf{i}, 2)$ & & & $0.3664 * * *$ & $(0.0339)$ & 0.0546 & $(0.0352)$ \\
\hline C (i,3) & & & & & 0.000007 & $(0.0458)$ \\
\hline$A(\mathbf{i}, 1)$ & 0.0120 & $(0.0355)$ & 0.0253 & $(0.0270)$ & -0.0009 & (0.0308) \\
\hline$A(i, 2)$ & $-0.1158 * * *$ & $(0.0304)$ & $-0.1841^{* * *}$ & $(0.0425)$ & $-0.0992 * * *$ & $(0.0229)$ \\
\hline$A(i, 3)$ & $-0.1474^{* * *}$ & $(0.0355)$ & $-0.1371^{* * *}$ & $(0.0351)$ & 0.2025 & $(0.0281)$ \\
\hline$G(\mathbf{i}, 1)$ & $0.9513^{* * *}$ & $(0.0070)$ & 0.0138 & $(0.0176)$ & 0.0063 & (0.0119) \\
\hline$G(\mathbf{i}, 2)$ & $-0.0273^{* * *}$ & $(0.0096)$ & $0.8342^{* * *}$ & $(0.0172)$ & $0.0267^{* * *}$ & $(0.0095)$ \\
\hline G $(\mathbf{i}, 3)$ & 0.0016 & $(0.0086)$ & $-0.0813^{* * *}$ & $(0.0214)$ & $0.9625^{* * *}$ & $(0.0067)$ \\
\hline D (i,1) & $0.3966 * * *$ & $(0.0266)$ & -0.0325 & $(0.0292)$ & -0.0379 & $(0.0432)$ \\
\hline$D(\mathbf{i}, 2)$ & $0.1367 * * *$ & $(0.0401)$ & $0.3094^{* * *}$ & $(0.0445)$ & 0.0227 & $(0.0362)$ \\
\hline D (i,3) & 0.0659 & $(0.0423)$ & 0.0330 & $(0.0432)$ & $0.2543^{* * *}$ & (0.0449) \\
\hline MVLB-Q(24) & & 201.35 & 46) & & & \\
\hline MVLB-Q(36) & & 305.84 & 83) & & & \\
\hline MVLB-Qs(24) & & 198.55 & 70) & & & \\
\hline MVLB-Qs(36) & & 301.69 & 81) & & & \\
\hline
\end{tabular}

Note: See note for Table A1-1. 
Table A3-4: Subsample (Jan 1 $1^{\text {st }}, 2008$ to Dec 31'st, 2012) estimation results - Malaysia

\begin{tabular}{|c|c|c|c|c|c|c|}
\hline \multirow[b]{2}{*}{$R_{i 1}(1)$} & \multicolumn{2}{|c|}{ USA(i=1) } & \multicolumn{2}{|c|}{$\mathrm{JPN}(\mathrm{i}=2)$} & \multicolumn{2}{|c|}{ MYS(i=3) } \\
\hline & $-0.0603 * *$ & $(0.0274)$ & $0.5698 * * *$ & $(0.0223)$ & $0.2039 * * *$ & $(0.0121)$ \\
\hline$R_{i 1}(2)$ & -0.0224 & $(0.0274)$ & $0.1450 * * *$ & $(0.0211)$ & $0.0434 * * *$ & $(0.0111)$ \\
\hline $\mathbf{R}_{\mathrm{i} 2}(\mathbf{1})$ & 0.0328 & $(0.0208)$ & $-0.1266^{* * *}$ & $(0.0208)$ & $-0.0391 * * *$ & $(0.0116)$ \\
\hline $\mathbf{R}_{\mathrm{i} 2}(2)$ & -0.0038 & $(0.0203)$ & -0.0162 & $(0.0192)$ & -0.0112 & $(0.0089)$ \\
\hline $\mathbf{R}_{\mathrm{i} 3}(\mathbf{1})$ & $-0.0768 * *$ & $(0.0374)$ & -0.0515 & $(0.0345)$ & $0.0467 * *$ & $(0.0234)$ \\
\hline $\mathbf{R}_{\mathrm{i} 3}(2)$ & -0.0072 & $(0.0400)$ & 0.0108 & $(0.0364)$ & $0.0707 * * *$ & $(0.0201)$ \\
\hline Constant & 0.0393 & $(0.0275)$ & -0.0243 & $(0.0278)$ & $0.0269 *$ & $(0.0153)$ \\
\hline$C(\mathbf{i}, 1)$ & $0.1515^{* * *}$ & $(0.0155)$ & 0.0615 & $(0.0615)$ & -0.0043 & $(0.0261)$ \\
\hline$C(\mathbf{i}, 2)$ & & & $0.3448 * * *$ & $(0.0320)$ & $0.0527 * *$ & $(0.0220)$ \\
\hline$C(\mathbf{i}, 3)$ & & & & & 0.0399 & $(0.0586)$ \\
\hline$A(\mathbf{i}, 1)$ & $-0.0700 * *$ & $(0.0344)$ & -0.0142 & $(0.0226)$ & 0.0531 & $(0.0388)$ \\
\hline$A(i, 2)$ & $0.1438^{* * *}$ & $(0.0286)$ & $0.1725^{* * *}$ & $(0.0343)$ & $0.0932^{* *}$ & $(0.0451)$ \\
\hline$A(i, 3)$ & $0.0711^{* * *}$ & $(0.0154)$ & 0.0214 & $(0.0140)$ & $0.2955^{* * *}$ & $(0.0291)$ \\
\hline G (i,1) & $0.9496 * * *$ & $(0.0053)$ & 0.0036 & (0.0189) & 0.0141 & $(0.0186)$ \\
\hline G (i,2) & -0.0154 & $(0.0109)$ & $0.8392^{* * *}$ & $(0.0159)$ & $0.1510^{* * *}$ & $(0.0392)$ \\
\hline G $(\mathbf{i}, 3)$ & $0.0156^{* * *}$ & $(0.0052)$ & $-0.0865^{* * *}$ & $(0.0192)$ & $0.9408 * * *$ & $(0.0143)$ \\
\hline$D(\mathbf{i}, \mathbf{1})$ & $0.3841^{* * *}$ & $(0.0248)$ & -0.0267 & $(0.0272)$ & 0.0358 & $(0.0628)$ \\
\hline$D(\mathbf{i}, \mathbf{2})$ & $0.0945^{* * *}$ & $(0.0323)$ & $0.2887 * * *$ & $(0.0390)$ & 0.0797 & $(0.0663)$ \\
\hline D (i,3) & $0.0782^{* * *}$ & $(0.0159)$ & 0.0237 & $(0.0206)$ & $-0.2551 * * *$ & $(0.0432)$ \\
\hline MVLB-Q(24) & & 173.25 & 3) & & & \\
\hline MVLB-Q(36) & & 270.89 & 56) & & & \\
\hline MVLB-Qs(24) & & 247.55 & 93) & & & \\
\hline MVLB-Qs(36) & & 338.88 & 36) & & & \\
\hline
\end{tabular}

Note: See note for Table A1-1. 
Table A3-5: Subsample (Jan 1st, 2008 to Dec 31st, 2012) estimation results - Philippines

\begin{tabular}{|c|c|c|c|c|c|c|}
\hline \multirow[b]{2}{*}{$\mathbf{R}_{\mathrm{i1}}(\mathbf{1})$} & \multicolumn{2}{|c|}{ USA(i=1) } & \multicolumn{2}{|c|}{ JPN(i=2) } & \multicolumn{2}{|c|}{ PHL(i=3) } \\
\hline & $-0.0706^{* *}$ & $(0.0284)$ & $0.5527 * * *$ & $(0.0224)$ & $0.4284^{* * *}$ & $(0.0194)$ \\
\hline$R_{i 1}(2)$ & -0.0353 & $(0.0287)$ & $0.1508 * * *$ & $(0.0176)$ & -0.0143 & $(0.0224)$ \\
\hline $\mathbf{R}_{\mathrm{i} 2}(\mathbf{1})$ & 0.0145 & $(0.0146)$ & $-0.1327 * * *$ & $(0.0255)$ & -0.0118 & $(0.0226)$ \\
\hline $\mathbf{R}_{\mathrm{i} 2}(2)$ & 0.0152 & $(0.0152)$ & 0.0064 & $(0.0190)$ & 0.0211 & (0.0189) \\
\hline $\mathbf{R}_{\mathrm{i} 3}(\mathbf{1})$ & 0.0091 & $(0.0251)$ & $-0.0604 * * *$ & $(0.0183)$ & $0.1382 * * *$ & $(0.0260)$ \\
\hline $\mathbf{R}_{\mathrm{i} 3}(2)$ & -0.0218 & $(0.0261)$ & 0.0105 & $(0.0167)$ & -0.0137 & $(0.0210)$ \\
\hline Constant & 0.0319 & $(0.0253)$ & -0.0115 & $(0.0256)$ & 0.0404 & $(0.0264)$ \\
\hline$C(\mathbf{i}, \mathbf{1})$ & $0.1547 * * *$ & $(0.0181)$ & $-0.1319^{* *}$ & $(0.0522)$ & 0.0632 & $(0.0651)$ \\
\hline$C(\mathbf{i}, 2)$ & & & $0.2556 * * *$ & (0.0339) & -0.0068 & $(0.0686)$ \\
\hline$C(\mathbf{i}, 3)$ & & & & & $0.3223^{* * *}$ & $(0.0535)$ \\
\hline$A(\mathbf{i}, \mathbf{1})$ & 0.0567 & $(0.0374)$ & 0.0143 & $(0.0245)$ & $-0.0864 * *$ & $(0.0232)$ \\
\hline$A(i, 2)$ & $0.1260 * * *$ & $(0.0269)$ & $0.2794 * * *$ & $(0.0372)$ & $-0.1537 * * *$ & $(0.0327)$ \\
\hline$A(i, 3)$ & $0.1458 * * *$ & $(0.0274)$ & -0.011 & $(0.0298)$ & $-0.2200 * * *$ & $(0.0477)$ \\
\hline G (i,1) & $0.9586 * * *$ & $(0.0032)$ & -0.0174 & $(0.0140)$ & -0.0250 & $(0.0183)$ \\
\hline$G(\mathbf{i}, 2)$ & -0.0054 & $(0.0101)$ & $0.8797 * * *$ & $(0.0213)$ & 0.0180 & $(0.0370)$ \\
\hline G (i,3) & 0.0078 & $(0.0091)$ & $-0.0595 * *$ & $(0.0271)$ & $0.8439 * * *$ & $(0.0359)$ \\
\hline D (i,1) & $-0.3987 * * *$ & $(0.0245)$ & $0.1262 * * *$ & $(0.0294)$ & $0.0922^{* *}$ & $(0.0470)$ \\
\hline$D(\mathbf{i}, 2)$ & $-0.1140^{* * *}$ & $(0.0436)$ & $0.3361 * * *$ & $(0.0677)$ & -0.0271 & $(0.0584)$ \\
\hline$D(\mathbf{i}, 3)$ & -0.0612 & $(0.0373)$ & $0.2033^{* * *}$ & $(0.0366)$ & $0.3946^{* * *}$ & $(0.0504)$ \\
\hline MVLB-Q(24) & & 186.91 & 44) & & & \\
\hline MVLB-Q(36) & & 287.11 & 08) & & & \\
\hline MVLB-Qs(24) & & 231.30 & 63) & & & \\
\hline MVLB-Qs(36) & & 316.29 & 99) & & & \\
\hline
\end{tabular}

Note: See note for Table A1-1. 
Table A3-6: Subsample (Jan 1 $1^{\text {st }}, 2008$ to Dec 31'st, 2012) estimation results - Thailand

\begin{tabular}{|c|c|c|c|c|c|c|}
\hline \multirow[b]{2}{*}{$\mathbf{R}_{\mathrm{i1}}(\mathbf{1})$} & \multicolumn{2}{|c|}{ USA(i=1) } & \multicolumn{2}{|c|}{ JPN(i=2) } & \multicolumn{2}{|c|}{ THA(i=3) } \\
\hline & $-0.0799 * * *$ & $(0.0266)$ & $0.5521^{* * *}$ & $(0.0221)$ & $0.3316^{* * *}$ & $(0.0211)$ \\
\hline $\mathbf{R}_{\mathrm{i1}}(\mathbf{2})$ & -0.0335 & $(0.0303)$ & $0.1382^{* * *}$ & $(0.0264)$ & $0.1805^{* * *}$ & $(0.0276)$ \\
\hline $\mathbf{R}_{\mathrm{i} 2}(\mathbf{1})$ & 0.0127 & $(0.0245)$ & $-0.1494 * * *$ & $(0.0253)$ & $-0.0653^{* *}$ & $(0.0259)$ \\
\hline $\mathbf{R}_{\mathrm{i} 2}(\mathbf{2})$ & -0.0105 & $(0.0229)$ & -0.0021 & $(0.0217)$ & 0.0246 & $(0.0212)$ \\
\hline $\mathbf{R}_{\mathrm{i3}}(\mathbf{1})$ & 0.0041 & $(0.0227)$ & 0.0363* & $(0.0185)$ & $-0.0771 * * *$ & $(0.0179)$ \\
\hline $\mathbf{R}_{\mathrm{i} 3}(\mathbf{2})$ & -0.0236 & $(0.0219)$ & 0.0063 & $(0.0187)$ & 0.0080 & $(0.0235)$ \\
\hline Constant & $0.0476^{*}$ & $(0.0267)$ & -0.0069 & $(0.0271)$ & $0.0860 * * *$ & (0.0329) \\
\hline$C(\mathbf{i}, \mathbf{1})$ & $0.1498^{* * *}$ & $(0.0206)$ & $0.1309 * * *$ & $(0.0473)$ & -0.0134 & $(0.0426)$ \\
\hline$C(\mathbf{i}, 2)$ & & & $0.2806^{* * *}$ & $(0.0329)$ & 0.0267 & $(0.0336)$ \\
\hline$C(\mathbf{i}, 3)$ & & & & & $0.1731^{* * *}$ & $(0.0310)$ \\
\hline$A(\mathbf{i}, \mathbf{1})$ & 0.0336 & $(0.0372)$ & $0.0401^{* *}$ & $(0.0184)$ & -0.0140 & $(0.0315)$ \\
\hline$A(i, 2)$ & $0.1673^{* * *}$ & $(0.0283)$ & $0.1652^{* * *}$ & $(0.0421)$ & 0.0394 & $(0.0283)$ \\
\hline$A(i, 3)$ & 0.0226 & $(0.0355)$ & $0.0569 * *$ & $(0.0257)$ & $0.2304 * * *$ & $(0.0379)$ \\
\hline G (i,1) & $0.9531^{* * *}$ & $(0.0063)$ & -0.0049 & $(0.0117)$ & 0.0071 & (0.0113) \\
\hline$G(\mathbf{i}, 2)$ & $-0.0132 *$ & $(0.0079)$ & $0.8839 * * *$ & $(0.0211)$ & 0.0086 & $(0.0126)$ \\
\hline G (i,3) & -0.0071 & $(0.0096)$ & -0.0158 & $(0.0161)$ & $0.9460 * * *$ & $(0.0090)$ \\
\hline D (i,1) & $-0.3733^{* * *}$ & $(0.0313)$ & $0.0509 *$ & $(0.0285)$ & -0.0374 & $(0.0304)$ \\
\hline$D(i, 2)$ & $-0.1763^{* * *}$ & $(0.0415)$ & $0.3406^{* * *}$ & $(0.0528)$ & -0.0095 & $(0.0355)$ \\
\hline D (i,3) & -0.0257 & $(0.0429)$ & $0.0747^{* *}$ & (0.0309) & $-0.2820 * * *$ & $(0.0425)$ \\
\hline MVLB-Q(24) & & 204.13 & $87)$ & & & \\
\hline MVLB-Q(36) & & 294.03 & 329) & & & \\
\hline MVLB-Qs(24) & & 229.40 & 534) & & & \\
\hline MVLB-Qs(36) & & 364.05 & 19) & & & \\
\hline
\end{tabular}

Note: See note for Table A1-1. 


\section{Figure A-1: Adjusted closing prices}

U.S.

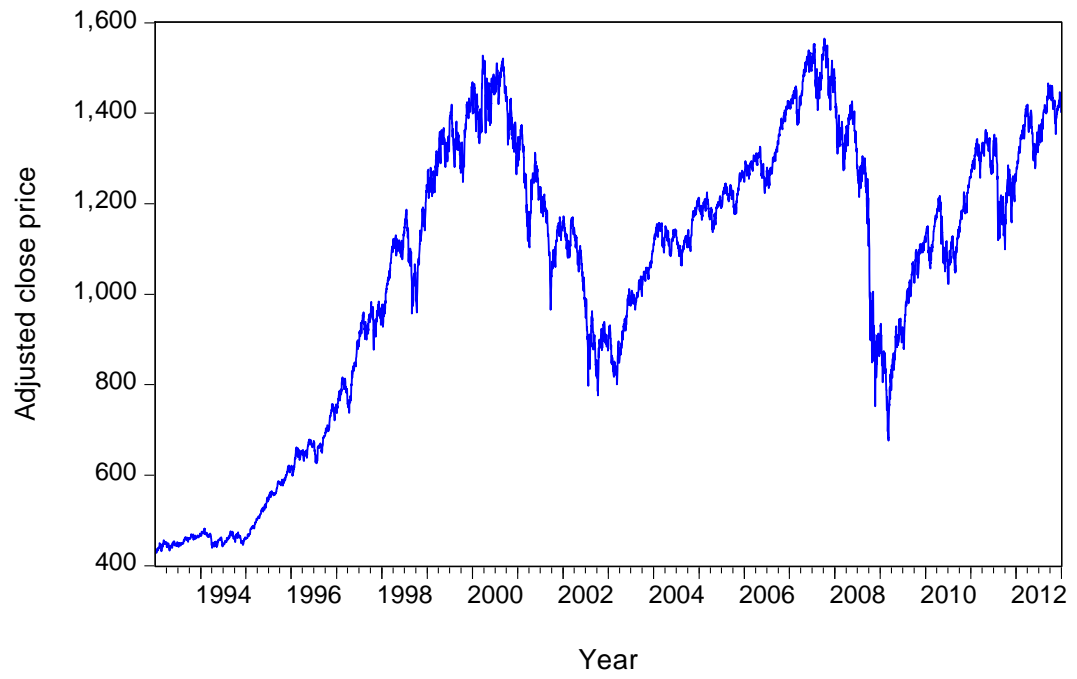

CHINA

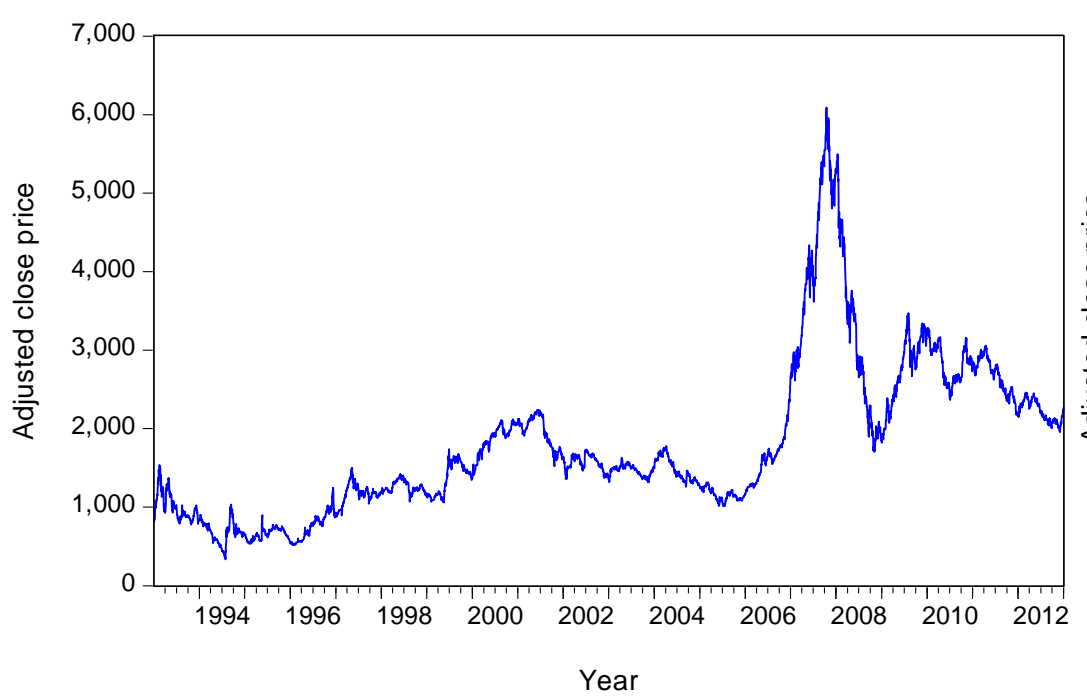

JAPAN

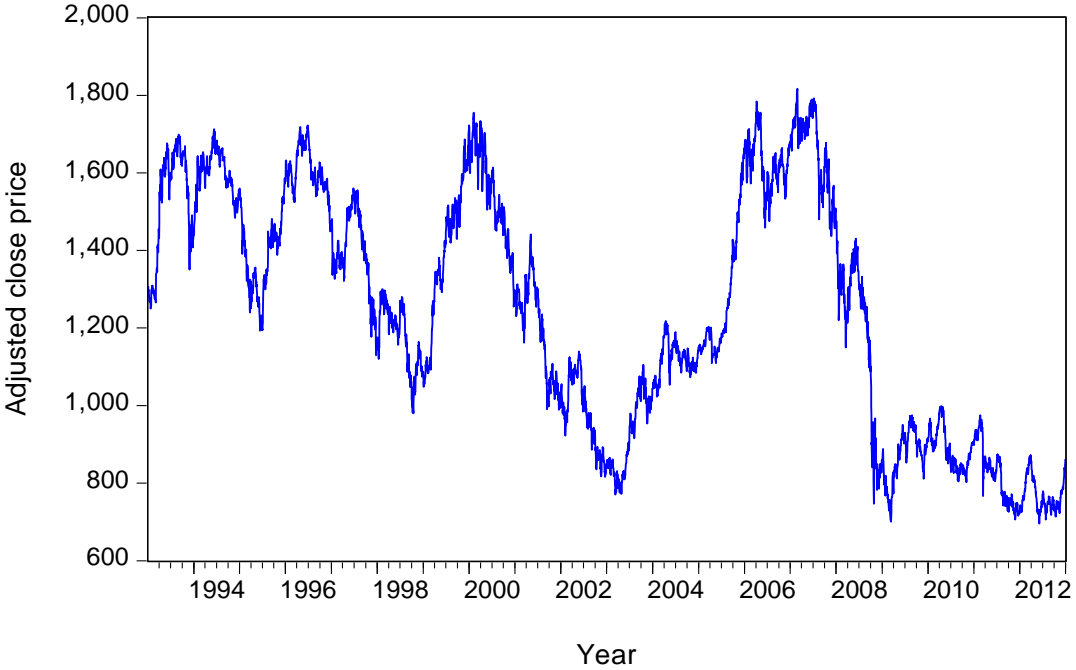

INDONESIA

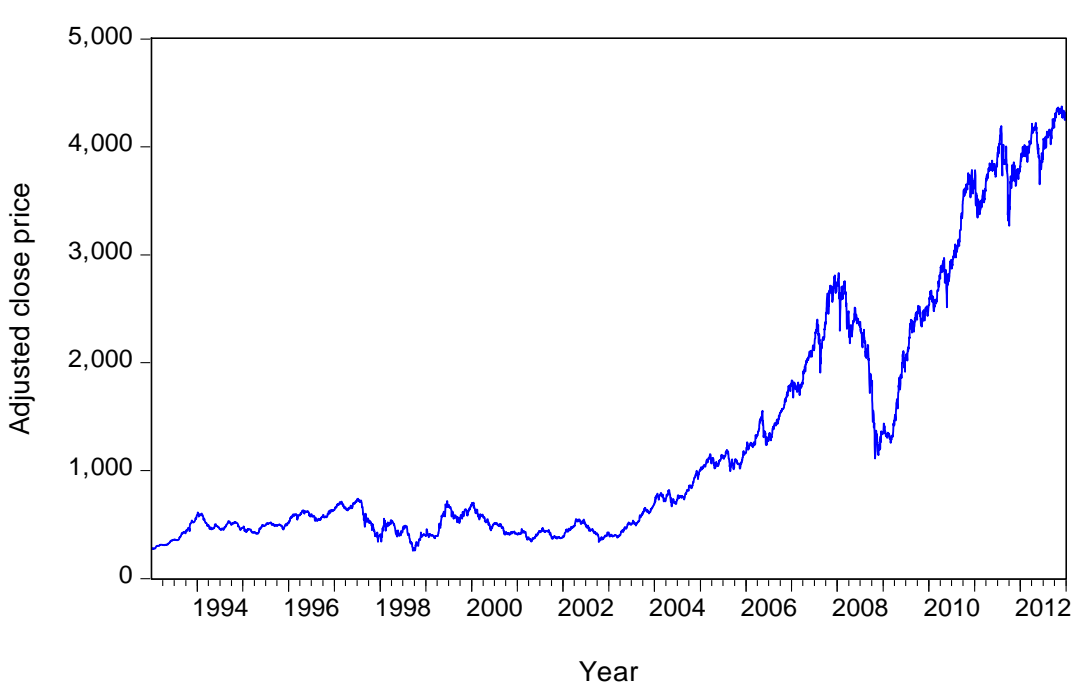


INDIA

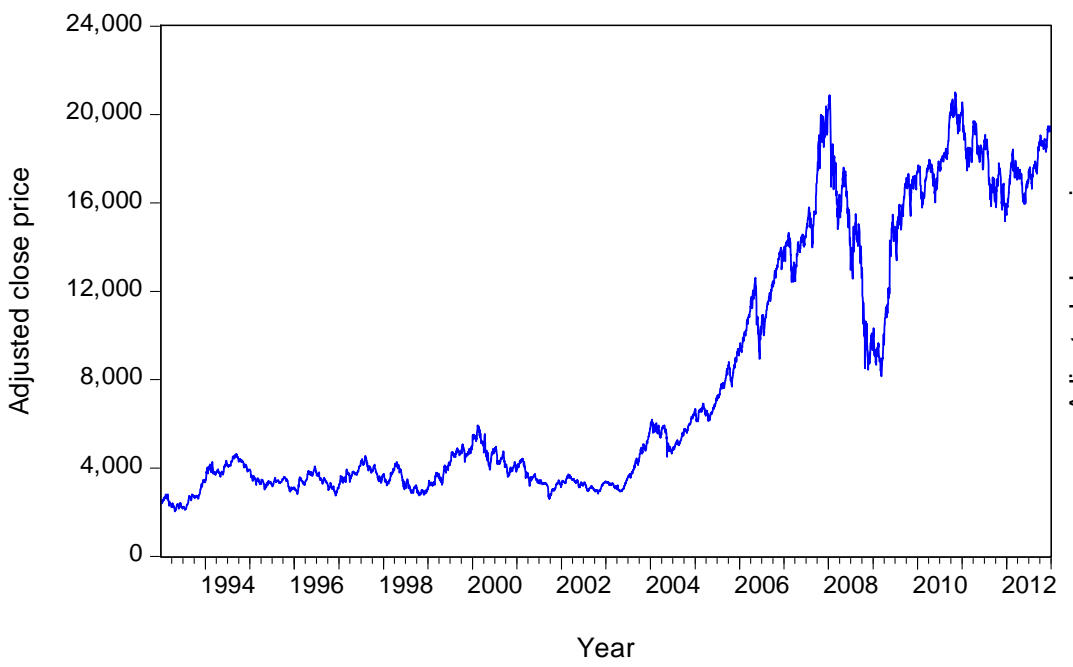

PHILIPPINES

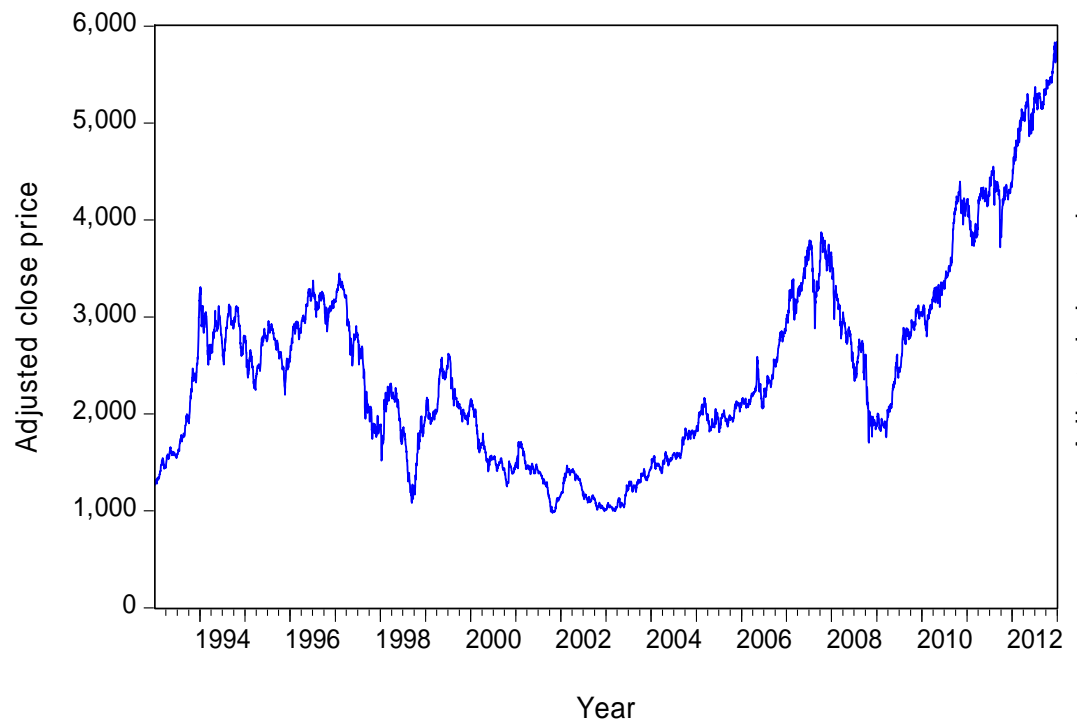

MALAYSIA

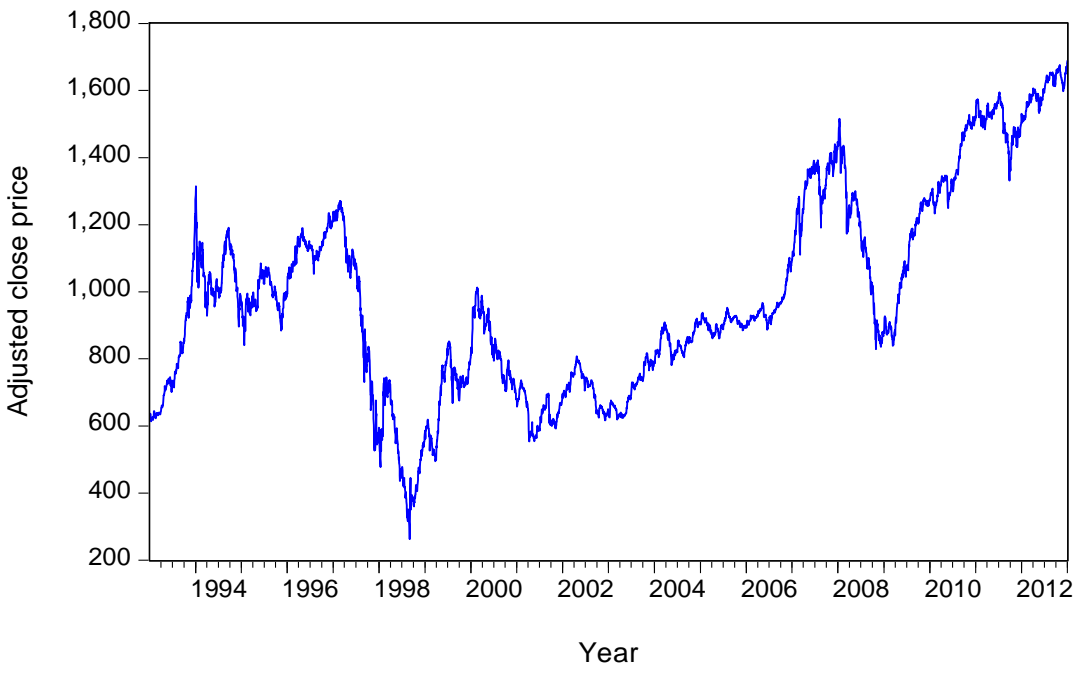

THAILAND

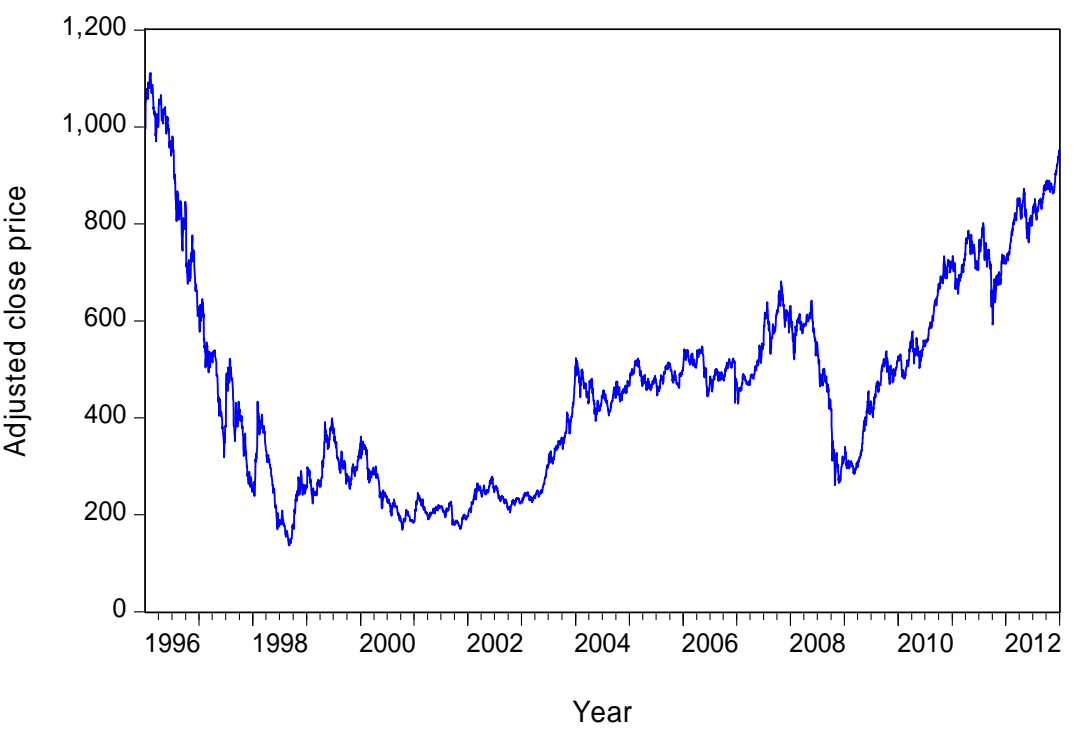


Figure A-2: Daily returns

U.S.

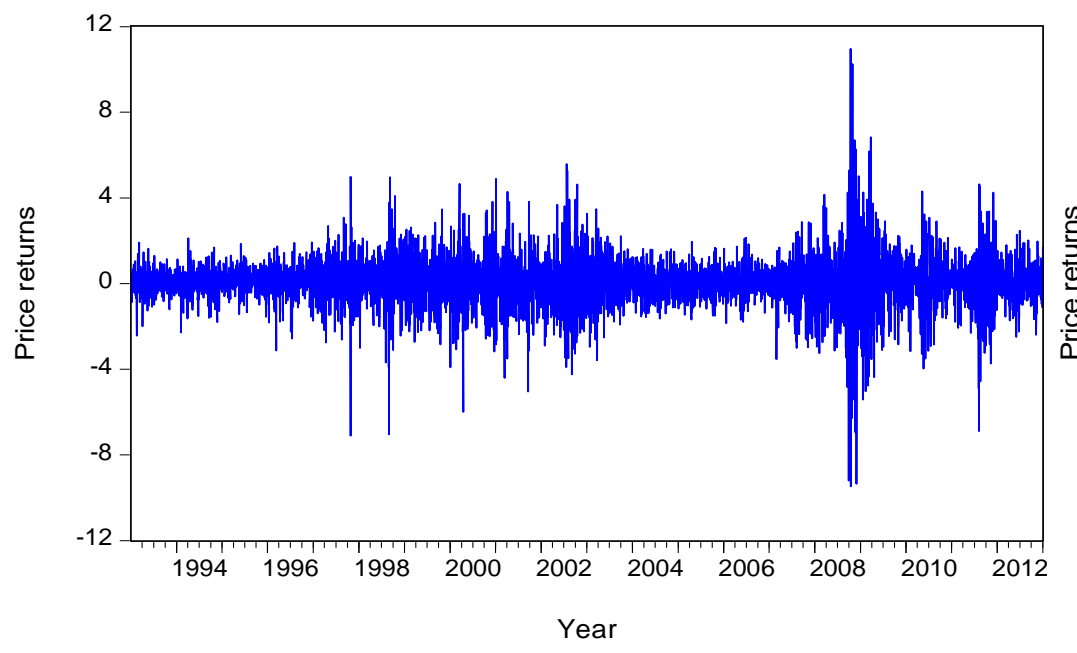

CHINA

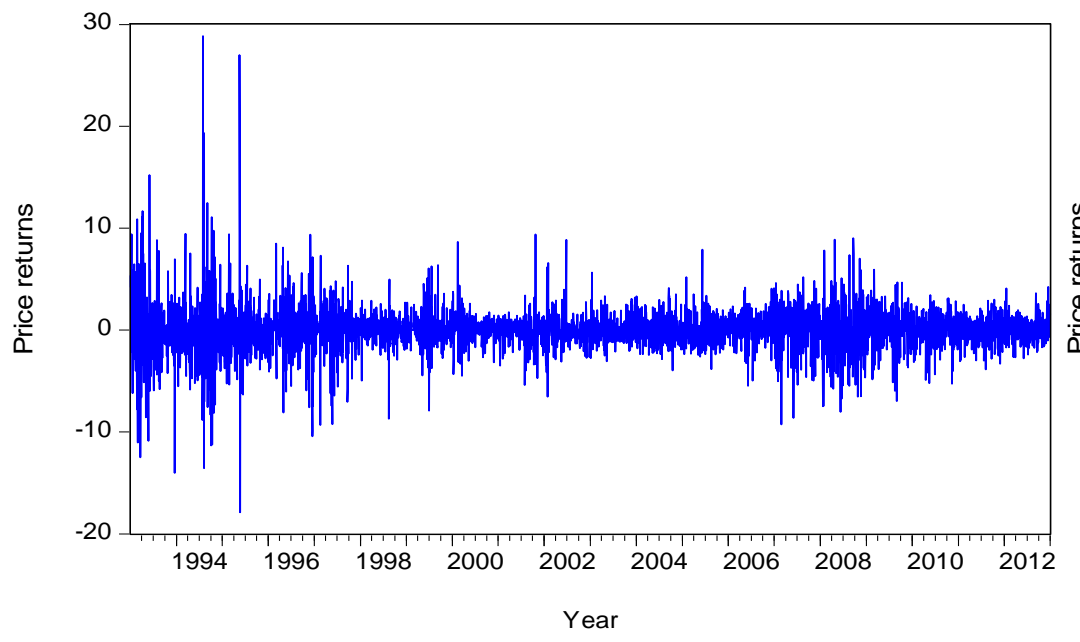

JAPAN

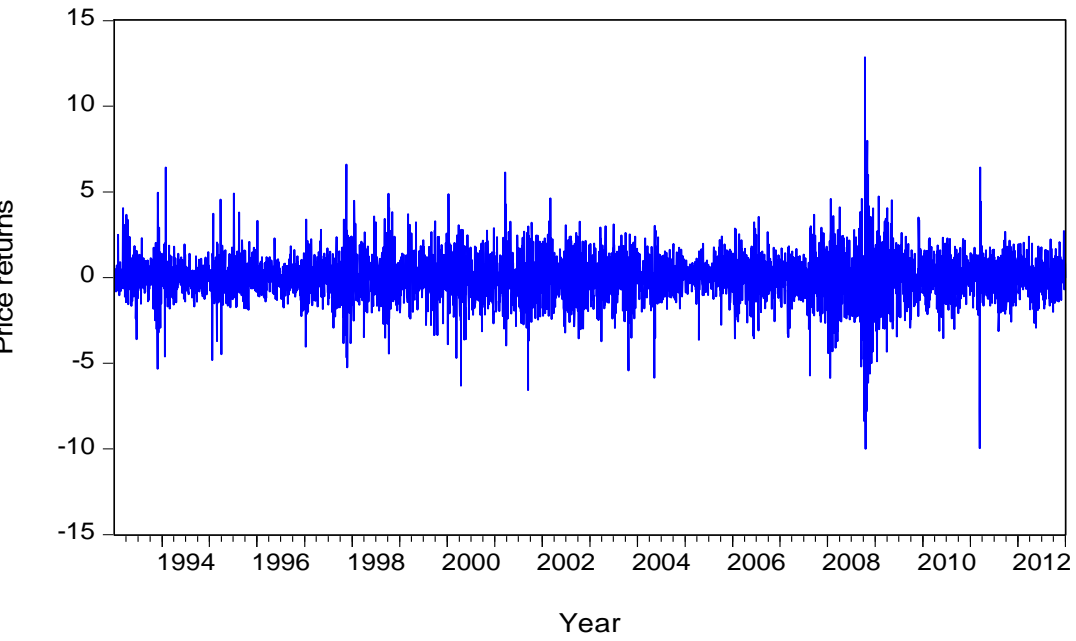

INDONESIA

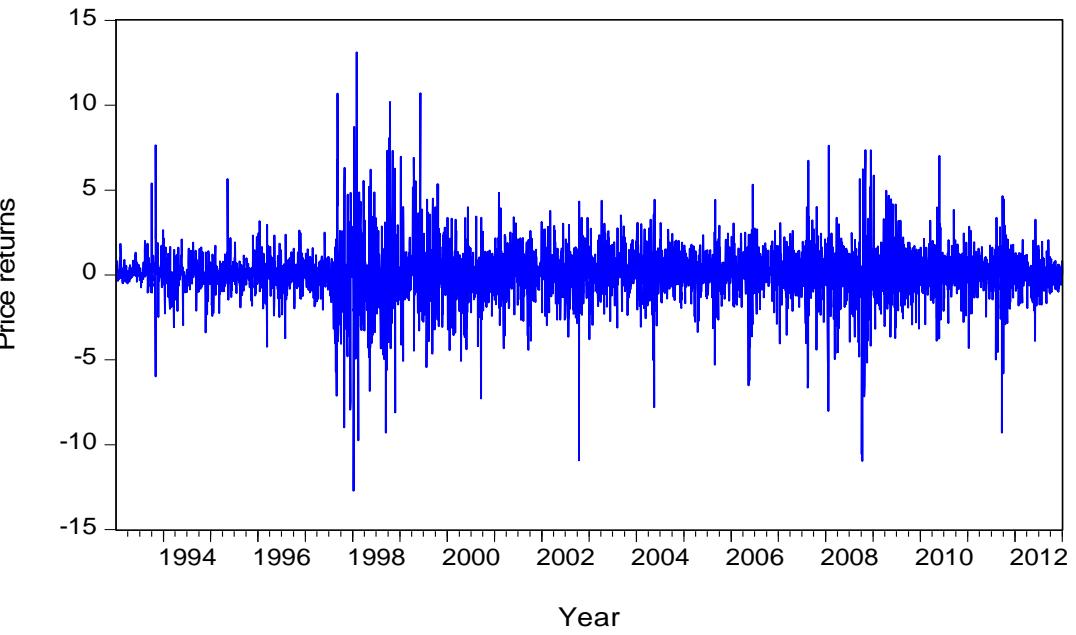


INDIA

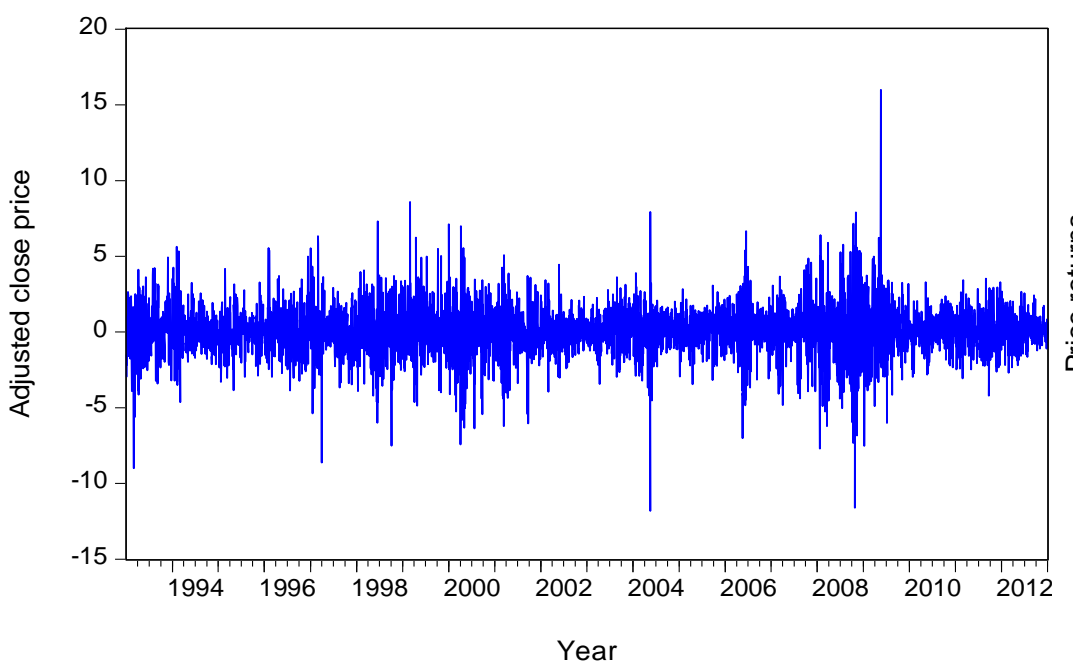

PHILIPPINES

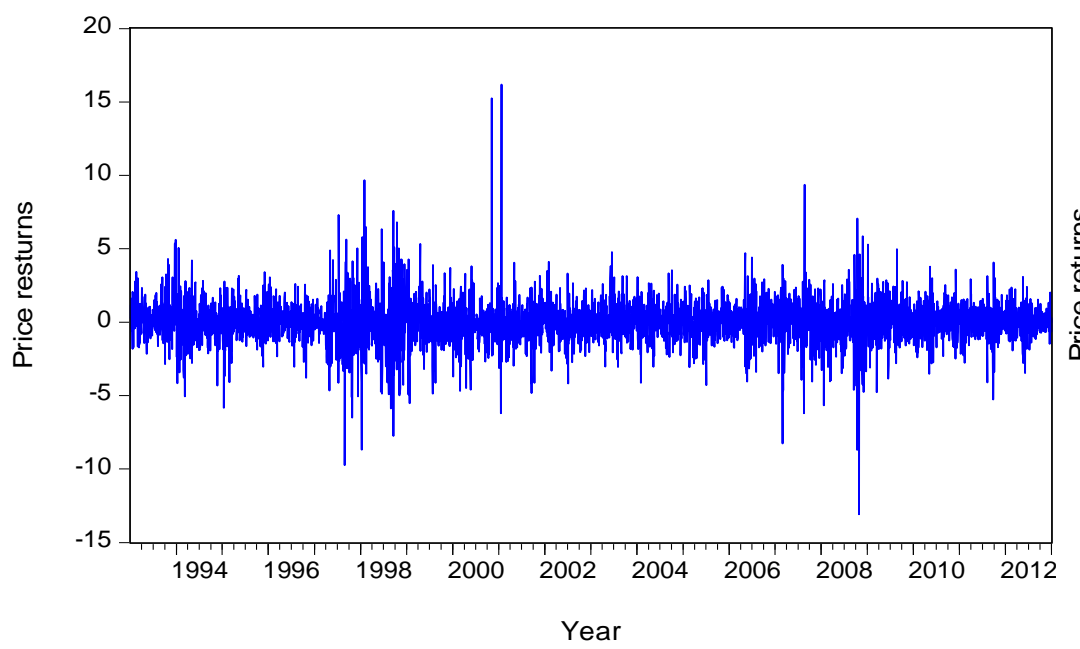

MALAYSIA

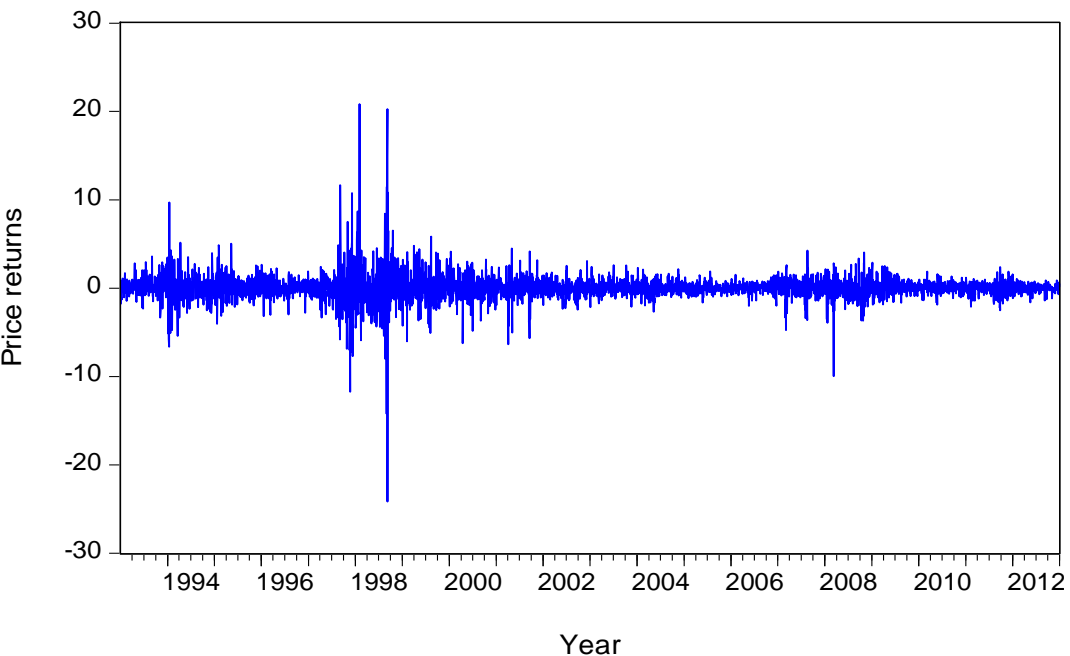

THAILAND

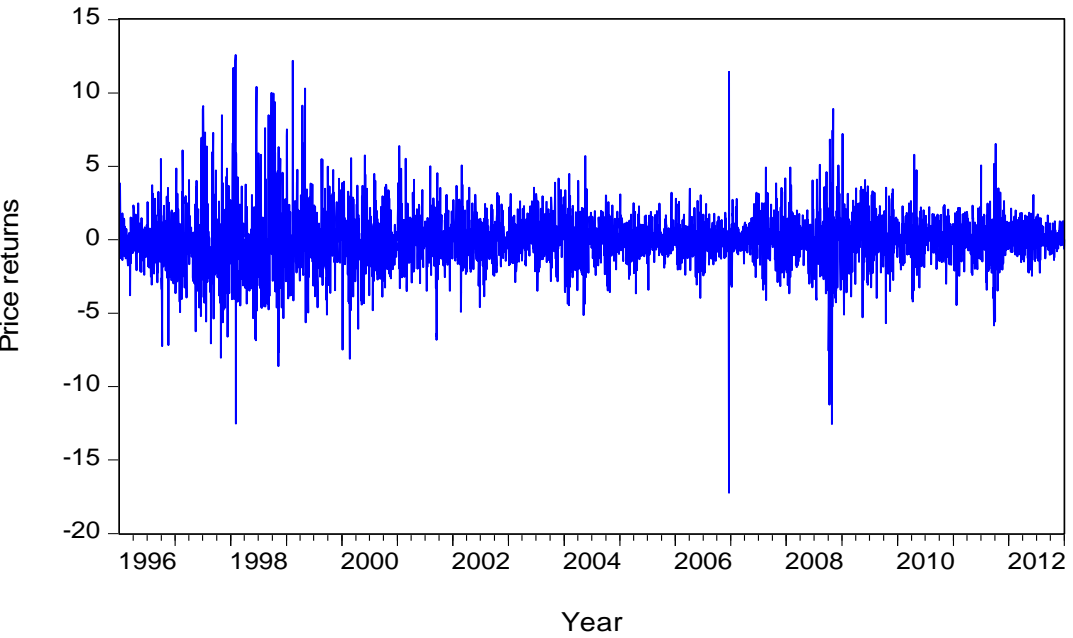

